\title{
A new theory of social roles in networks
}

\author{
Ramona Roller, Frank Schweitzer
}

\begin{abstract}
Theories of social roles neglect social clusters. However, accounting for clusters is essential because individuals in social networks (e.g., social media) cannot oversee the whole network and have to restrict their interactions to local substructures. Roles which do not account for this cluster formation may lead to misinterpretations of the network's dynamics and functions. This article proposes a theory of social roles in large social networks. We group roles detected in previous empirical studies into meta-roles and embed them along two dimensions, strategicness describing whether the person works towards a particular goal or not, and the type of strategy (selfish or group-oriented). We extend this framework by adding a cluster dimension describing to what extent a person's interactions are embedded locally or globally in the network. We argue that empirical role analyses would benefit from our theory by systematically accounting for complex structures specific to the network perspective, generalising empirical findings beyond individual case studies, and understanding human interactions better.
\end{abstract}

Keywords: social role, theory, communication network, cluster, role detection

\section{Introduction}

Detecting social roles of individuals is a key method to understand why individuals interact with others. Traditionally, social scientists have applied role detection to small groups where they qualitatively analysed direct interactions between individuals in unconnected case studies (Bales, 1950; Belbin, 2010; Benne \& Sheats, 1948). Roles emerge from these interactions in a bottom-up fashion and describe patterns of communication behaviour such as disseminating information, mediating between several factions, and censoring. More recently, researchers have started to apply role detection to social networks which represent interactions and relations between individuals as connections. Networks contain a large number of individuals and connections, and display complex structures that are neither purely regular nor purely random, such as the formation of groups. In contrast, groups are smaller in size and contain simpler structures, such as fully-connected structures allowing for one-to-all communication (Fig. 1).

Despite these differences, role detection analyses in networks do not account for network-specific complex structures which leads to a flawed detection of roles. Moreover, role detection in networks adheres to using case studies, the approach of small group research (Benamar et al., 2017; Combs Turner et al., 2005; de Valck et al., 2009). Results of these case studies are not interrelated in an overarching framework and therefore cannot be used to systematically advance insights and theory-building in role detection. 
To study roles beyond small groups, we are faced with the need for a theory that accounts for complex structures of social networks and provides a generalising framework to connect isolated case studies.

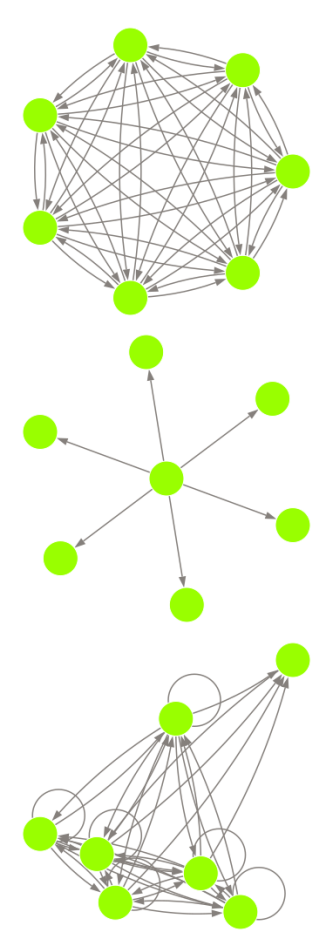

(a) Small group

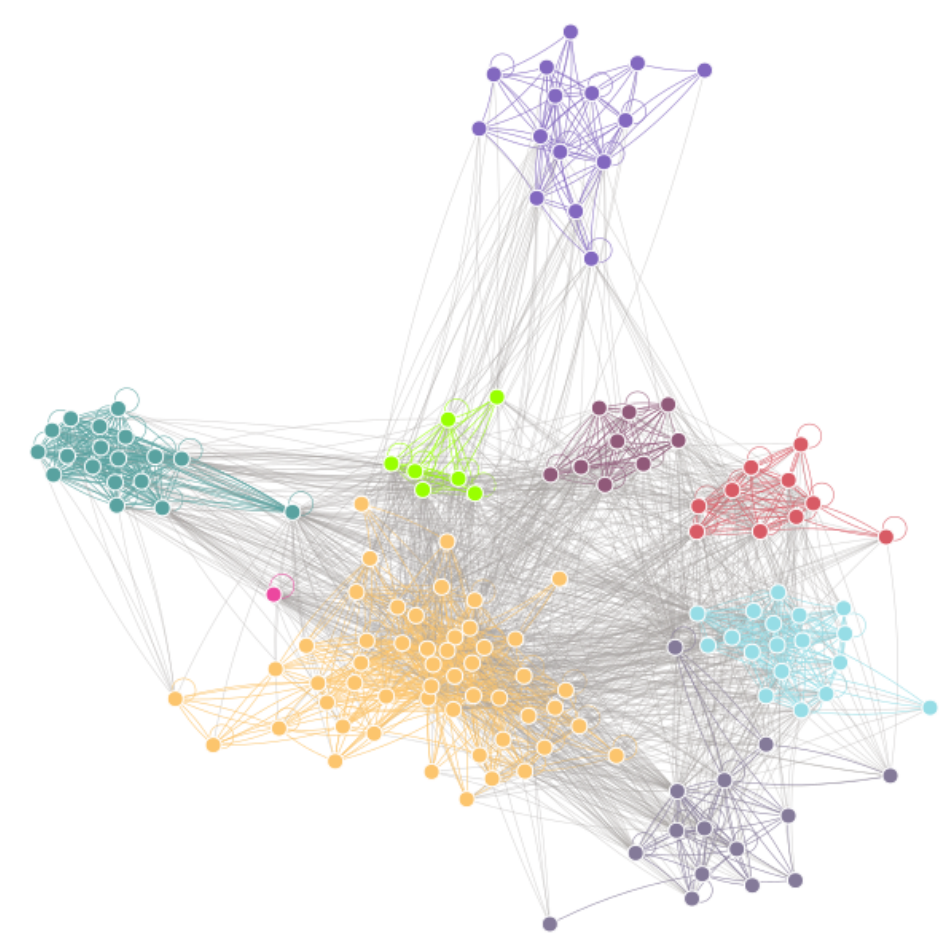

(b) Large social network

Figure 1: Comparison between a small group and a large social network. A group is fully connected because every member can communicate with all other members (Fig. 1a top). A group displays a one-to-all communication because communication capacity is not restrictive (Fig. 1a centre). A group may represent a cluster of a network (Fig. 1a bottom corresponds to the green cluster in Fig. 1b). A network displays more complex structures, such as clusters (coloured nodes) because connections are only dense in some parts of the network (Fig. 1b).

In this article, we propose a theory of social roles. We argue that an important characteristic of networks are clusters, the tendency of individuals to form groups with stronger attachment within groups than between groups. Clusters are known under different synonyms but are also often mixed up with similar yet different names (Fig. 2). Synonyms for cluster are community and module in network research and group in classic sociology. In network research, clusters may derive from many clusterings, closed connections among groups of three individuals. Clusterings describe a local structure which defines global clusters if it is measured for all groups of three in the whole network (Newman, 2006). 
Groups may also form if nodes with similar attributes, called labels, are grouped. These labels are external to the network and are provided in a top-down fashion. For example, in an e-mail communication network, individuals may be grouped by place of residence. This distinguishes label-based groups from clusters which emerge in a bottom-up fashion from connections among individuals. In classic sociology, clusters define groups of people sharing the same purpose, norms, identity, or values (Putnam, 1995). If moral values are applied to these clusters, the clusters become hierarchically organised and display social inequalities (Therborn, 2012). As a consequence, the clusters become social divisions (Ribbens McCarthy \& Edwards, 2011). If these social divisions persist across individuals and generations we speak of social stratification (Bottero, 2005; Giddens \& Sutton, 2017).

Clusters in networks form because individuals have a limited communication capacity, cannot oversee the global network, and therefore restrict their interactions to groups (de Sola Pool \& Kochen, 1978; Dunbar, 1992). Since individuals differ in resources and attributes individuals prefer to interact with similar others, leading to homophilic clusters (Lazarsfeld \& Merton, 1954; McPherson et al., 2001). Clusters make social life more manageable as they facilitate social learning (Henrich \& McElreath, 2003) and the allocation of limited resources (Sapolsky, 2004), minimise opportunism (Coleman, 1998), mitigate conflict (Simmel, 1964), and maximise individual motivation (Halevy et al., 2011) and group productivity (Koski et al., 2015). Clusters shape social roles by indicating how individuals are expected to behave toward one another (Halevy et al., 2011; Koski et al., 2015; Savin-Williams, 1979). 


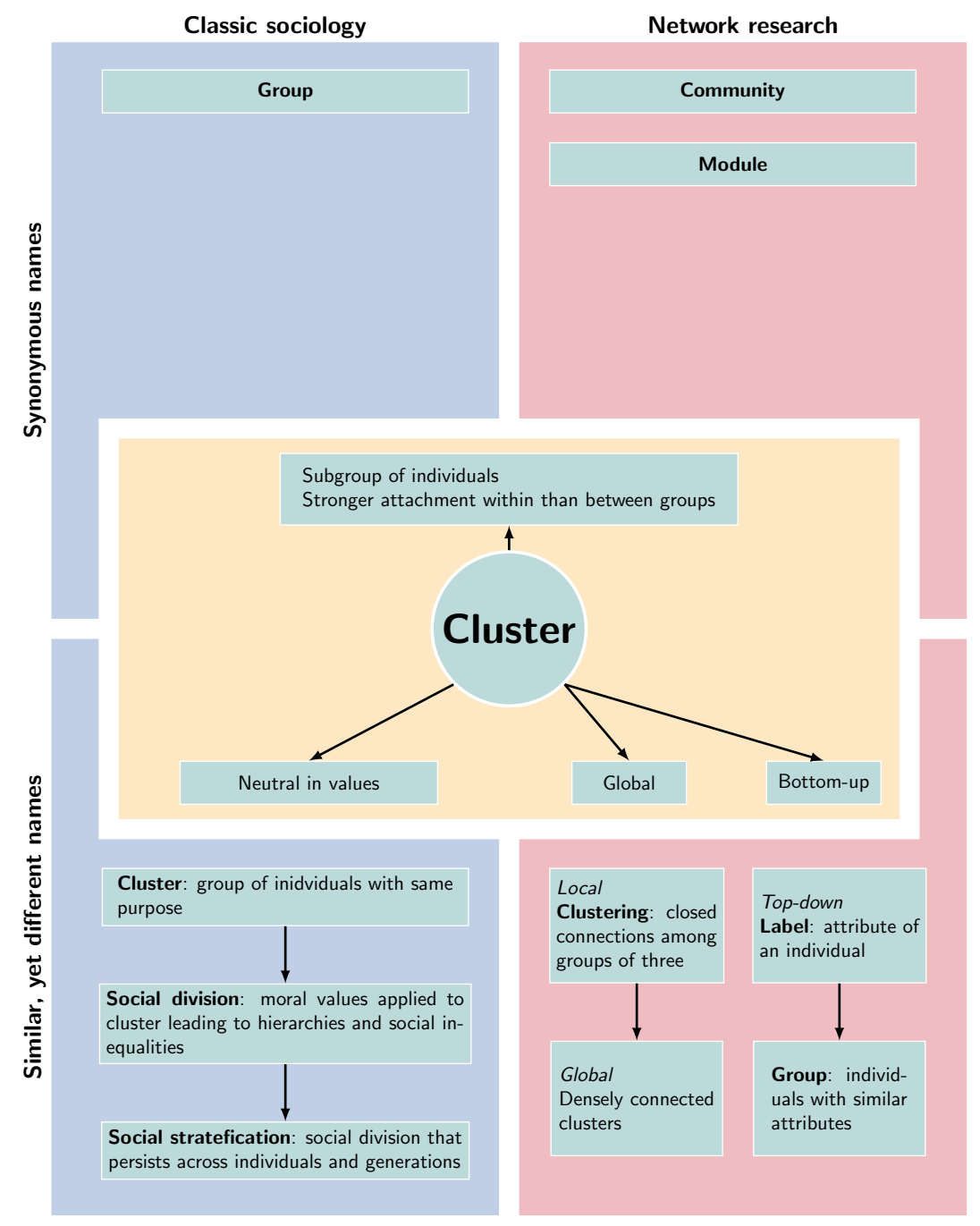

Figure 2: Disambiguating the cluster concept. Clusters are groups of individuals in a network with stronger attachment within groups than between groups. Synonyms are communities and modules in network research and groups in classic sociology. Clusters are global structures because they are defined for the whole network. In contrast, clustering refers to a local structure because it considers the number of closed connections among groups of three individuals. Clusters are bottom-up structures because they emerge from interaction patterns of nodes in the network. In contrast, labels are top-down structures because they are external to the network and pre-defined by the researcher. Clusters are non-hierarchical and neutral in values. In contrast, social divisions are clusters with moral values that become hierarchically organised and display social inequalities. If these divisions are persistent in individual behaviour and across generations we speak of social stratification. 


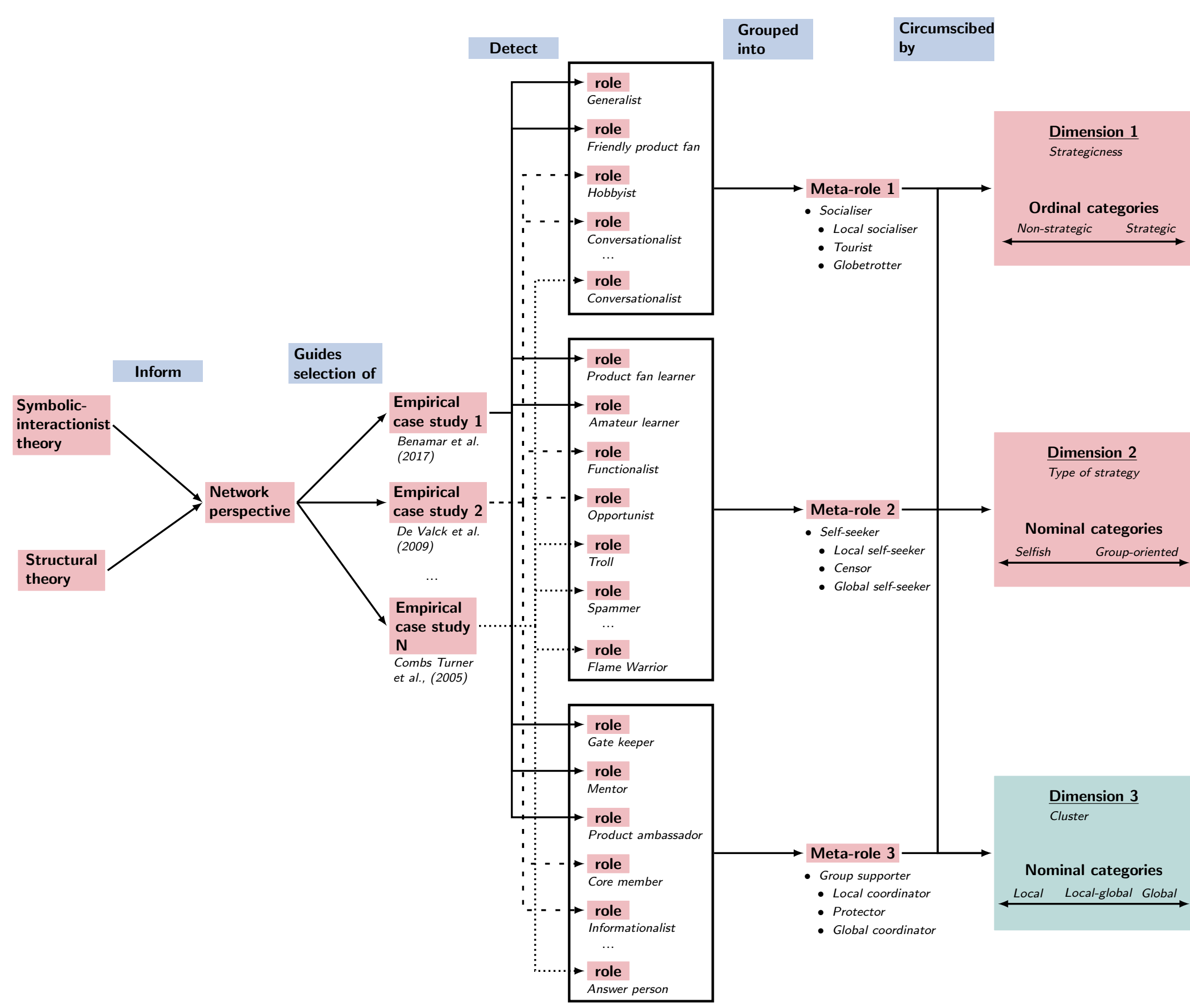

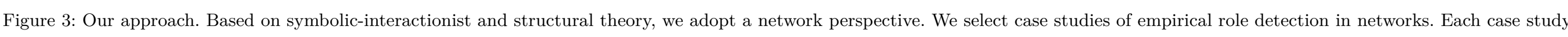

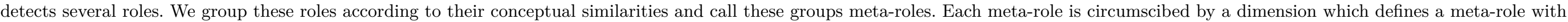

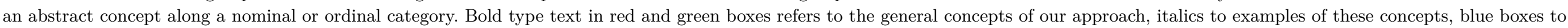
transitions between concepts. Dimension 1 and 2 (red) were extracted from the reviewed case studies and Dimension 3 (green) extends this perspective. 
To build our theory, we examine existing empirical studies on role detection in large social networks and find that the detected roles are very similar and can be grouped into meta-roles. A meta-role is an umbrella term that summarises several roles. We work out three meta-roles: socialiser, self-seeker, and group supporter. For example, the socialiser communicates for the sake of fun without pursuing a planned goal. We circumscribe and interrelate the meta-roles along two dimensions. A dimension represents ordinal or nominal categories of an abstract concepts to which the meta-roles are qualitatively assigned. For example, the abstract concept of strategicness describes the skill of individuals to target their actions towards achieving a certain goal. Strategicness can be defined along two ordinal categories indicating whether an individual is (high) or is not (low) strategic. The meta-role of the socialiser is categorised to have low strategicness.

We extend these meta-roles with the cluster dimension to build an extended theory of social roles. The cluster dimension is defined along three nominal categories indicating whether interactions occur locally within clusters, globally without clusters, or between clusters. By adding the cluster dimension, each of the meta-roles is split into three new meta-roles. For example, the meta-role of socialiser is split into the meta-roles local socialiser, tourist, and globetrotter. The local socialiser, the tourist, and the globetrotter communicate in a non-strategic way and just want to stay in touch with others. Whereas the local socialiser mainly communicates with individuals from her own cluster, the tourist also communicates with individuals from different clusters. The globetrotter cannot be clearly assigned to a cluster and communicates with individuals from many clusters. Figure 3 summarises our approach.

Our approach builds a theory from empirical research. We need such a theory to identify typical interaction patterns in social networks, understand under which circumstances they occur, measure and predict them empirically, and validate them. Addressing roles in social networks, this theory is embedded into classical symbolic-interactionist and structural theories (Biddle, 1986), rather than providing an alternative explanatory mechanism of role formation. It identifies the interaction patterns that form a role rather than identify the effects roles have on individuals or social processes (e.g., social stratification).

\section{Theory of communication roles}

\subsection{Conceptualising 'role' and 'theory'}

What is a social role? It refers to the behaviour expected of someone who holds a particular position in a group (Macionis, 2017). In everyday life, individuals fulfill several kinds of roles, often to different extents. For example, a professor is associated with roles such as teaching, mentoring, supervising, publishing, and doing research. 
In some settings, holding a position which is officially recognised by some authority (e.g., society, institutions) is considered a role in itself (e.g., professor, mother, spouse). We call these roles 'formal roles' and distinguish them from 'informal roles', which we study in this article. Formal roles are independent of the context, defined in a topdown fashion by some authority, and stable over time. In contrast, informal roles are context-specific, develop in a bottom-up manner through local interactions, and are flexible over time. Informal roles are important because they improve the functioning of the group and inform newly established formal roles (Ang \& Zaphiris, 2010; Johnson et al., 2013; Krackhardt \& Stern, 1988). Informal roles strongly shape communication among individuals. In future empirical work, we aim to empirically measure roles with topological network measures.

A theory of social roles should define and interrelate roles which are to be expected in a communication network. It should specify the flexible behavioural causes of roles in the form of interactions because we develop it in a network context. The proposed theory neither relates roles to static, external causes (e.g., institutions, cultural norms), nor addresses the effect of these roles on individuals or societal processes (e.g., stratification). The proposed theory is useful if it can be successfully used for validating roles in empirical studies. The development of this theory will therefore reach into the future.

There already exist classic sociological theories that explain the formation of roles from different perspectives, such as symbolic-interactionist, structural, and functionalist theories. However, these theories provide explanations based on general sociological approaches which are too broad and do not incorporate network interdependencies among individuals. While they account for how individuals interact with each other, they neither account for the fact that individuals move in social groups and form clusters, nor for the fact that these clusters affect personal interactions. Still, classic theories provide a useful overarching framework in which our network-specific theory can be embedded. In this way, they serve as guidelines rather than explicit explanatory mechanisms.

\subsection{Embedding role theory into classic sociological approaches}

Since we are interested in informal roles which emerge out of interactions in a specific context we adopt a micro-sociological perspective manifesting in symbolic-interactionist theory and structural theory. Symbolic-interactionist theory emphasizes socio-psychological dynamics of individuals interacting with others (Blumer, 1969; Mead, 1934). Roles are situational as they are created within interactions. A role is the reponse to others' behaviour and roles cannot be adopted outside these interactions.

Like symbolic-interactionist theory, structural theory focuses on the impact of the local environment (behaviours towards others) on roles. In addition, it emphasizes the social position of individuals in a system which determines their behaviours toward others. Individuals with the same behavioural patterns fulfill the same role and form a social 
structure. The structural perspective layed the foundation for mathematical descriptions of roles, such as networks (Burt, 1976; 1982).

In contrast to symbolic-interactionist and structural theories, functionalist and conflict role theories adopt a macro-sociological perspective and are concerned with how broad aspects of society, such as institutions and large social groups, influence the social world. Functionalist theory sees society as a system of interconnected parts that work together in harmony to maintain a state of balance and social equilibrium for the whole (Linton, 1936; Parsons, 1951). Each of these parts contributes a different function to society, e.g., education offers a way to transmit a society's skills, knowledge, and culture to its youth, and politics provides a means of governing members of society. Roles are defined externally by societal norms and imposed on the individual. Like the institutions of society, individuals fulfill different functions by executing different roles.

Whereas functionalist theory assumes a cooperative society, conflict theory assumes a competitive one where different groups compete for power and resources (Marx, 1859). Roles are defined by dominance relations and help to establish hierarchies among different groups. In addition, both functionalist and conflict theories assume that roles are stable (e.g., due to norms) and that some consensus of what the roles are exists in the society (e.g., shared goal). These assumptions do not hold in large communication networks and are not made by the symbolic-interactionist and structural theories.

The assumptions of stability and top-down allocation of functionalist and conflict theories are also present in organisational role theory but on a smaller scale. This theory focuses on social organisations that are preplanned, task-oriented, and hierarchical (Gross et al., 1958; Kahn et al., 1964). Roles in such organisations are assumed to be associated with identified social positions and to be generated by normative expectations. However, norms may vary among individuals and may reflect both the official demands of the organisations and the pressures of informal groups.

Symbolic-interactionist and structural theories focus on socio-structural patterns whereas cognitive role theory focuses on individual characteristics and how they give rise to roles. It examines relationships between role expectations and behaviour and social conditions that give rise to expectations. It develops techniques for measuring expectations and their impact on social conduct. It is concerned with ways in which a person perceives the expectations of others and with the effects of those perceptions on behavior.

All in all, we see that our network perspective is not captured by theories that focus on a top-down allocation of roles, such as functionalist, conflict, organisational, and cognitive theory, but is best embedded into symbolic-interactionist and structural theories. 


\subsection{Previous research: theory-less case studies}

Similar to our approach (Fig. 3), classic studies of role detection have also embedded their analyses into symbolic-interactionist theory. In contrast to our approach, they did not make use of structural theory. As a consequence, studies focused on small, task-oriented groups to describe how roles emerge from interactions of individuals.

The foundation of this classic work was laid by Benne and Sheats (1948) who studied discussion groups. Participants where presented a problem, had to discuss it, and eventually find a consensus. The authors observed interactions during the discussion and qualitatively grouped these interactions into behavioural patterns. This grouping resulted in three role categories, task-, maintenance-, and self-centered roles, each being comprised of about ten specific communication roles (see Appendix A for a complete description of all roles). Group task roles focus on completing the group's goal. Examples include the initiator-contributor who elicits facts and information from other individuals and the orienter who guides the discussion, keeping it on track. Group-building and maintenance roles focus on building interpersonal relationships and maintaining harmony. Examples include the harmonizer who tries to resolve conflict between group members and the gatekeeper who regulates conversations so that everyone can have a say. Self-centered roles focus on preventing the group from reaching goals and on disrupting it. Examples include the aggressor who attacks other individuals' ideas and contributions in order to maintain high personal status and the recognition seeker who seeks to have their own contributions acknowledged by the group. Variations of this classic role classification are still widely used today (De Wever et al., 2008; Savelsbergh et al., 2012; Strijbos et al., 2004).

Similar to Benne and Sheats (1948), Bales (1950) adopted a trisection of roles focusing on differences in valence. In his interaction process analysis (IPA), the author developed a coding scheme for group interactions which categorizes twelve behaviours into a neutral, a positive and a negative category. The neutral category refers to task behaviours including all interactions necessary for task-completion. Examples include giving suggestions and asking for opinions. In case these behaviours lead to conflict if individuals disagree positive socio-emotional behaviours can restore group harmony. Examples include giving support and joking. In contrast, negative socio-emotional behaviours damage interpersonal relations, such as showing antagonism and withholding help. Appendix B summarises the complete IPA coding scheme.

IPA laid the basis for the five-stage group development model (Tuckman, 1965; Tuckman \& Jensen, 1977). Groups are assumed to sequentially proceed through five distinct stages, forming, storming, norming, performing, adjourning, each being associated with different IPA interaction patterns. For example, the performing stage should be dominated by task-related behaviour. However, recent empirical research has differentiated this theory as groups may not attain all stages (Rickards \& Moger, 2000), may not 
progress sequentially (Gersick, 1991), and may not abruptly change their interaction patterns (Arrow, 1997).

Towards the end of the 20th century, the focus shifted from group- to team-oriented research. Teams have a very close structure and are more task-focused than groups. Belbin (2010) developed a taxonomy of team roles based on qualitative observational studies similar to the one of Benne and Sheats (1948). Students at a management training college were put into groups and had to solve management case studies. Their contributions to and interactions with the team were observed and analysed. Belbin (2010) found eight roles including the monitor evaluator who analyses ideas and evaluates their feasibility and the plant who provides innovative ideas to the team (see Appendix $\mathrm{C}$ for detailed descriptions of all roles).

These classic studies are well-embedded into classic sociological approaches, yet they suffer from several shortcomings that impede their usefulness in forming a general theory of social roles. These studies are based on small, task-oriented groups which differ greatly from large communication networks in terms of size, context, interdependence, self-perception, and communication style (DeVito, 2014).

Size Classic studies examine groups that are small enough that all members can communicate with relative ease as both senders and recipients. In contrast, networks comprise many more individuals and local clusters, and are shaped through hierarchies, social homophily, geographical or language restrictions. As such, they prevent that everyone communicates with everyone else.

Context Classic studies examine communication that takes place in a small, stable, and clearly defined context whereas the context of networks is broad, flexible, and illdefined. Thus, individuals in groups share a common purpose and organising rules because they interact with each other for similar reasons. In contrast, in networks, the context determines to what extent the purpose and the organising rules of the global structure or the local group are salient (Hornsey \& Hogg, 2000; Tajfel \& J. Turner, 1979; J.C. Turner et al., 1987). This context may be defined by relative size of offline societal groups, such as ethnicities, or foci (Hofstra et al., 2017). The authors showed that the larger the offline ethnic group the more homogenous are its members on online platforms because they have more opportunities to meet similar others. The more individuals share foci, social, psychological, legal, or physical entity around which joint activities are organized (Feld, 1981), the more likely they are to share friends online. Moreover, weaker forms of similarity than a shared purpose or rules may shape networks.

Interdependencies Classic studies rely on groups that are characterised by strong, simple interdependence because the behaviour of one member affects all other members. For example, Giardini and Wittek (2019) identified six interdependencies between the 
sender, receiver, and object of gossip which indicate under what conditions a sender decides to share or not to share gossip. In contrast, complex interdependence between local and global structures in networks lead to global phenomena that are more than the sum of their local parts (Mitchell, 2006).

Self-perception Members of groups have a strong self-perception as a group because they feel that they are part of a larger whole. This may also be the case in networks, however, in addition, members may also strongly identify with their local group because of their limited communication capacity (Dunbar, 1992; Miritello et al., 2013a,b; Saramäki et al., 2014).

Communication styles Individuals in groups use one-to-all communication whereas in networks they often use one-to-one or one-to-many communication and message forwarding because these behaviours become easier in a digital environment (Fig. 1). This communication style also affects clustering because it fosters the formation of internally homogenous but mutually dissimilar groups, which may become culturally isolated (Keijzer et al., 2018).

All in all, this comparison shows that classic studies of roles in groups are not applicable to networks. Networks are large, generate flexible contexts, form complex interdependencies and self-perception structures, and use a variety of communication styles.

To overcome these differences, modern studies have applied role detection to networks with several methods, ranging from qualitative analyses where roles are known a priori (Gleave et al., 2009; Golder \& Donath, 2004; Nolker \& Zhou, 2005), over equivalencebased approaches using block models (Borgatti \& Everett, 1989; Karrer \& Newman, 2011; White et al., 1976), to advanced computational methods such as matrix factorisation (Costa \& Ortale, 2012; Henderson et al., 2012; Ruan \& Parthasarathy, 2014; Zhao et al., 2013). However, many of these works are purely technical and often theory-free, leaving out any interpretation of the detected roles. Those studies that do provide an interpretation are case studies and neither relate nor explain roles with a general theory. These studies either conduct a purely explorative analysis without using any theory at all, or use a highly specific theory which only applied to the research context at hand (e.g., online forums (Golder \& Donath, 2004), coalitions of political interest groups (BoxSteffensmeier et al., 2018), virtual learning environments (Waters \& Gasson, 2005), or gossiping (Giardini \& Wittek, 2019). To our knowledge, no previous study made use of a general theory of communication roles in the study of social roles in communication networks. 


\subsection{Towards a generalised approach: socialiser, self-seeker, and group supporter}

Despite the unstructured variety of previous studies, their detected roles show some similarities which we can generalise. We qualitatively group empirical roles into three meta-roles, socialiser, self-seeker, and group supporter, and define these meta-roles along two dimensions, strategicness and type of strategy (Fig. 3). In this way, we connect isolated case studies and uncover shared patterns, the meta-roles.

For example, as shown in Figure 3, Benamar et al. (2017) and Combs Turner et al. (2005) represent two case studies each detecting different roles in different settings. Benamar et al. (2017) analysed a dicussion forum on Facebook and Combs Turner et al. (2005) a discussion forum on Usenet. Both case studies detected roles which are characterised by selfish and purpose-driven behaviour, such as the product fan learner (Benamar et al., 2017) and the flame warrior (Combs Turner et al., 2005). We group these roles together and distill their conceptual similarities into the meta-role of the self-seeker. To capture the conceptual characteristics of the self-seeker and the empirical roles that are grouped under it we circumscribe the self-seeker with the dimensions of strategicness and type of strategy. We do this by categorising the self-seeker as strategic, an ordinal category of the strategicness dimension and as selfish, a nominal category of the type of strategy dimension. Other empirical roles such as the generalist (Benamar et al., 2017) or the answer person (Combs Turner et al., 2005) are conceptually different from the self-seeker. They are grouped into the other two meta-roles, socialiser and group supporter. Like the self-seeker these meta-roles are circumscibed by the oridinal and nominal categories of the dimensions.

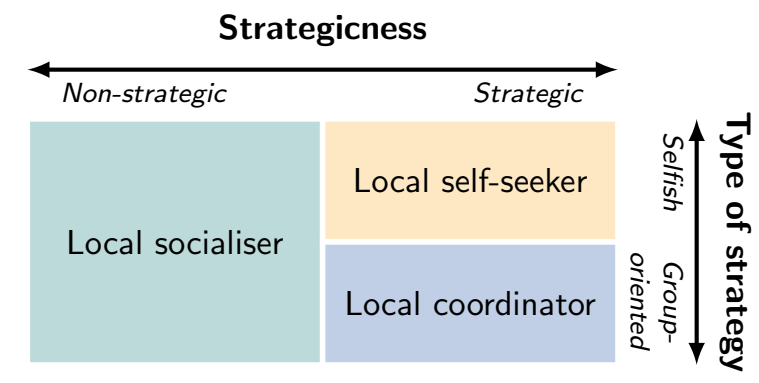

Figure 4: The simple approach to generalise empirical roles into meta-roles without network structures. Three meta-roles, socialiser, self-seeker, and group supporter are defined along two dimensions: strategicness and type of strategy.

This procedure yields a generalising approach which does not incorporate complex network structures but is only defined by simple, small group structures (Fig. 4). We therefore refer to it as 'simple approach' and to its meta-roles as 'simple meta-roles' 
(Fig. 6, left box). This simple approach represents the first step towards developing our theory of social roles.

In the following, we define the three simple meta-roles and the conceptual dimensions of strategicness and type of strategy. Table 1 summarises the mapping of empirical roles to the simple meta-roles and Appendix D provides a description of all empirical roles and the corresponding studies we reviewed.

Socialiser The socialiser communicates to keep in touch with others rather than to focus on goals or tasks set by herself or the group. For example, the amateur role, identified in a Facebook group about a cooking product, seeks to share aspect of her daily life with the group and socialises around the cooking practice (Benamar et al., 2017). We map the amateur role to our socialiser role.

Self-seeker The self-seeker exploits information flow for her own interest. She is not interested in group goals, tries to deprive others of information, and ensures that she knows what's going on. For example, the flame warrior role, detected in an online discussion forum, uses harsh and negative debate to 'win' an argument and thereby makes herself appear superior to others in the conversation (Combs Turner et al., 2005). We map the flame warrior role to our self-seeker role.

Group supporter The group supporter ensures that individuals comply to group norms and are involved in the community, gets task-related activities moving, and initiates contact by introducing individuals to one another. For example, the appraiser role, detected in an online community on aviation, increases the motivation of the community by recognizing the achievement of others, encouraging further involvement and creativity and ensure that individuals comply to the community's cultural norms (Seraj, 2012). We map the appraiser to our group supporter role.

To conceptually explain and relate these meta-roles, we embed them along two Boolean dimensions: strategicness and type of strategy (Fig. 4). Strategicness indicates whether someone acts in a determined way to achieve a certain goal (strategic) or in a spontaneous way to take things as they come (non-strategic). If a person is strategic her type of strategy indicates whether the person would like to achieve her own goal (selfish) or the one of the group (group-oriented).

The socialiser is non-strategic because she wanders around looking for opportunities to socialise irrespective of her own or group-related tasks and purpose. Of course, one could argue that socialising is a selfish goal in itself, but it is not planned and does not systematically exclude (selfish) or include (group-oriented) goals of others as in the strategic case. The self-seeker follows a selfish strategy because she only tries to achieve her own goals irrespective of the ones of the group. In contrast, the group supporter 
follows a group-oriented strategy because she directs her own actions and the ones of others toward achieving the group's purpose.

Although this simple theoretical framework of communication roles summarises detected roles in previous research well, it is incomplete because it lacks complex structures which are common in large networks. Therefore, we extend the framework by adding a cluster dimension. 
Table 1: Mapping empirical roles onto the simple meta-role of the socialiser. The socialiser communicates to keep in touch with others rather than to focus on goals or tasks set by herself or the group

\begin{tabular}{|c|c|c|c|}
\hline \multirow{2}{*}{$\begin{array}{ll} & \text { This approach } \\
\text { Role } & \\
\end{array}$} & \multicolumn{3}{|c|}{ Previous work } \\
\hline & Research context & Classify roles by ... & Author \\
\hline \multicolumn{4}{|l|}{ Qualitative } \\
\hline Mingler focuses on short-term satisfaction and values social intercourse. & \multirow{2}{*}{$\begin{array}{l}\text { Online discussion } \\
\text { forum }\end{array}$} & \multirow{2}{*}{$\begin{array}{l}\text { observing user behaviour and grouping them into four roles: mingler, } \\
\text { insider, tourist, devotee, along two dimensions: intensity of user-product } \\
\text { and user-user relation, respectively. }\end{array}$} & \multirow[t]{2}{*}{ Kozinets (1999) } \\
\hline Insider values social intercourse. & & & \\
\hline Conversationalist enjoys discussing and communion. & $\begin{array}{l}\text { Online discussion } \\
\text { forum }\end{array}$ & $\begin{array}{l}\text { visually inspecting descriptive statistics of users' posting activities, such } \\
\text { as the number of sent messages. }\end{array}$ & $\begin{array}{l}\text { Combs Turner } \\
\text { et al. (2005) }\end{array}$ \\
\hline $\begin{array}{l}\text { Chatter posts a lot of messages to a few individuals but does not con- } \\
\text { tribute to the community conversation as a whole. }\end{array}$ & $\begin{array}{l}\text { Online discussion } \\
\text { forum }\end{array}$ & $\begin{array}{l}\text { conceptually pre-defining roles of users in an online discussion forum } \\
\text { and manually comparing them with selected topological network mea- } \\
\text { sures of users from the communication network of all users. }\end{array}$ & $\begin{array}{l}\text { Nolker and Zhou } \\
(2005)\end{array}$ \\
\hline Discussion person frequently reciprocates messages from many users. & $\begin{array}{l}\text { Online discussion } \\
\text { forum }\end{array}$ & $\begin{array}{l}\text { handcoding user messages and visually relating the resulting content } \\
\text { groups with structural properties of users' ego-networks (e.g., density } \\
\text { of edges in periphery) extracted from the communication network of all } \\
\text { users. }\end{array}$ & $\begin{array}{l}\text { Gleave et al. } \\
(2009)\end{array}$ \\
\hline Player entertains the community. & $\begin{array}{l}\text { Online discussion } \\
\text { forum }\end{array}$ & $\begin{array}{l}\text { manually coding users' messages and user interviews along Miles et al. } \\
(2019) .\end{array}$ & Seraj (2012) \\
\hline $\begin{array}{l}\text { Initiator maintains a social network of individuals by sending work- } \\
\text { unrelated messages to many individuals. }\end{array}$ & $\begin{array}{l}\text { Online learning } \\
\text { forum }\end{array}$ & $\begin{array}{l}\text { manually coding users' messages along an extended version of Garrison } \\
\text { et al. (2001) coding dimensions of teaching, social, and cognitive. }\end{array}$ & $\begin{array}{l}\text { Waters and Gas- } \\
\text { son }(2005)\end{array}$ \\
\hline Socializer emphasizes with individuals and enjoys jokes. & Online game & $\begin{array}{l}\text { observing players' interactions and grouping them into four roles: so- } \\
\text { cialiser, killer, achiever, explorer, along two dimensions: individuals vs } \\
\text { world focus, introvert vs extrovert. }\end{array}$ & Bartle (1996) \\
\hline \multicolumn{4}{|l|}{ Quantitative } \\
\hline $\begin{array}{l}\text { Conversationalist is socially involved but doesn't have high expertise on } \\
\text { the discussion topic. }\end{array}$ & \multirow[t]{2}{*}{$\begin{array}{l}\text { Online discussion } \\
\text { forum }\end{array}$} & \multirow{2}{*}{$\begin{array}{l}\text { applying k-means clustering to users' survey scores about usage of dis- } \\
\text { cussion forum (e.g., amount of supplied information to discussion) and } \\
\text { comparing resulting clusters with an ANOVA. }\end{array}$} & \multirow[t]{2}{*}{$\begin{array}{l}\text { de Valck et al. } \\
(2009)\end{array}$} \\
\hline Hobbyist uses the community for leisure and entertainment. & & & \\
\hline $\begin{array}{l}\text { Social network uses social chitchat rather article collaboration to build } \\
\text { strong relationships with other users. }\end{array}$ & $\begin{array}{l}\text { Online discussion } \\
\text { forum }\end{array}$ & $\begin{array}{l}\text { using a linear regression to infer handcoded content groups of user mes- } \\
\text { sages (roles) from structural properties of users' ego-networks derived } \\
\text { from the communication network of users. }\end{array}$ & $\begin{array}{l}\text { Welser et al. } \\
(2011)\end{array}$ \\
\hline Socialiser contributes with social interactions rather than ideas. & $\begin{array}{l}\text { Online discussion } \\
\text { forum }\end{array}$ & $\begin{array}{l}\text { applying k-means and hierarchical clustering to users' topological mea- } \\
\text { sures of their communication network (e.g., number of sent messages, } \\
\text { i.e. out-degree) and users' feature of platform usage (e.g., number of } \\
\text { posted ideas), and comparing resulting clusters with an ANOVA. }\end{array}$ & $\begin{array}{l}\text { Füller et al. } \\
(2014)\end{array}$ \\
\hline Generalist focuses on community life and social intercourse. & \multirow{2}{*}{$\begin{array}{l}\text { Online discussion } \\
\text { forum }\end{array}$} & \multirow{2}{*}{$\begin{array}{l}\text { handcoding user messages and visually relating the resulting content } \\
\text { groups to descriptive statistics of users' activity features (e.g., time } \\
\text { spent in the discussion group) and to structural properties of users' ego- } \\
\text { networks (e.g., number of sent messages (out-degree)) extracted from } \\
\text { the communication network of all users. }\end{array}$} & \multirow{2}{*}{$\begin{array}{l}\text { Benamar et al. } \\
(2017)\end{array}$} \\
\hline $\begin{array}{l}\text { Friendly product fan engages in animation activities, and community } \\
\text { life. }\end{array}$ & & & \\
\hline Immersion-focused enjoys the story-telling aspect of the game. & \multirow{2}{*}{ Online game } & \multirow{2}{*}{$\begin{array}{l}\text { conducting a factor analysis based on players' likert scale scores on sur- } \\
\text { vey questions such as 'I like to feel powerful in the game.. }\end{array}$} & \multirow{2}{*}{ Yee $(2006)$} \\
\hline Relationship-focused forms supportive relationships with others. & & & \\
\hline $\begin{array}{l}\text { Social player nurtures a friendly and welcoming atmosphere within the } \\
\text { community. }\end{array}$ & Online game & $\begin{array}{l}\text { applying a block model to shared interaction types of players and } \\
\text { analysing ego-network structures within and relations between blocks. }\end{array}$ & $\begin{array}{l}\text { Ang and Zaphiris } \\
(2010)\end{array}$ \\
\hline
\end{tabular}


Table 2: Mapping empirical roles onto the simple meta-role of the self-seeker. The self-seeker exploits information flow for her own interest. She is not interested in group goals, tries to deprive others of information, and ensures that she knows what's going on.

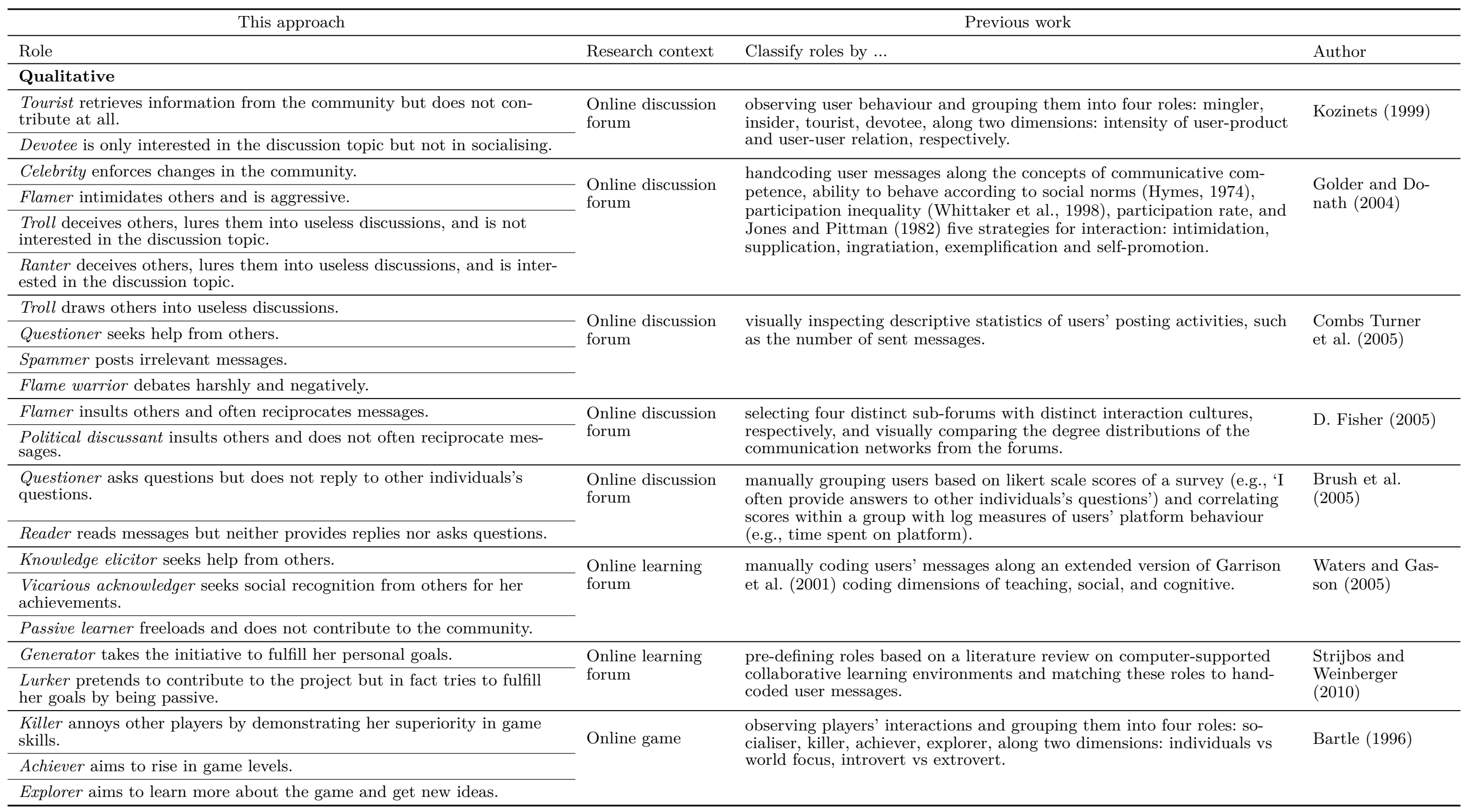


Table 2: Mapping empirical roles onto the simple meta-role of the self-seeker (cont).

\begin{tabular}{|c|c|c|c|}
\hline \multirow{2}{*}{$\begin{array}{ll} & \text { This approach } \\
\text { Role } & \end{array}$} & \multicolumn{3}{|c|}{ Previous work } \\
\hline & Research context & Classify roles by ... & Author \\
\hline \multicolumn{4}{|l|}{ Quantitative } \\
\hline $\begin{array}{l}\text { Functionalist retrieves information from the community but does not } \\
\text { contribute often. }\end{array}$ & \multirow[t]{2}{*}{$\begin{array}{l}\text { Online discussion } \\
\text { forum }\end{array}$} & \multirow{2}{*}{$\begin{array}{l}\text { applying k-means clustering to users' survey scores about usage of dis- } \\
\text { cussion forum (e.g., amount of supplied information to discussion) and } \\
\text { comparing resulting clusters with an ANOVA. }\end{array}$} & \multirow[t]{2}{*}{$\begin{array}{l}\text { de Valck et al. } \\
(2009)\end{array}$} \\
\hline $\begin{array}{l}\text { Opportunist retrieves information from the community but does not } \\
\text { contribute at all. }\end{array}$ & & & \\
\hline Active member mainly talks about herself and posts a lot. & \multirow[t]{2}{*}{$\begin{array}{l}\text { Online discussion } \\
\text { forum }\end{array}$} & \multirow{2}{*}{$\begin{array}{l}\text { handcoding user messages along five dimensions, including empathetic } \\
\text { content and user-centered content and comparing the resulting user } \\
\text { groups to regular equivalent users computed on the communication net- } \\
\text { work with the Continuous REGE algorithm of the UCINET software. }\end{array}$} & \multirow[t]{2}{*}{ Pfeil et al. (2011) } \\
\hline Passive member mainly talks about herself but does not post a lot. & & & \\
\hline $\begin{array}{l}\text { Product fan learner uses the community to improve her own skills and } \\
\text { knowledge. }\end{array}$ & \multirow[t]{3}{*}{$\begin{array}{l}\text { Online discussion } \\
\text { forum }\end{array}$} & \multirow{3}{*}{$\begin{array}{l}\text { handcoding user messages and visually relating the resulting content } \\
\text { groups to descriptive statistics of users' activity features (e.g., time } \\
\text { spent in the discussion group) and to structural properties of users' ego- } \\
\text { networks (e.g., number of sent messages (out-degree)) extracted from } \\
\text { the communication network of all users. }\end{array}$} & \multirow[t]{3}{*}{$\begin{array}{l}\text { Benamar et al. } \\
(2017)\end{array}$} \\
\hline Amateur learner uses the community to share her achievements. & & & \\
\hline $\begin{array}{l}\text { Friendly learner uses the community to improve her own skills and } \\
\text { knowledge. }\end{array}$ & & & \\
\hline $\begin{array}{l}\text { Teammate does not cooperate with other interest groups because their } \\
\text { goals are not aligned with hers }\end{array}$ & \multirow[t]{2}{*}{$\begin{array}{l}\text { Dyadic } \\
\text { communication }\end{array}$} & \multirow{2}{*}{$\begin{array}{l}\text { extracting topological network measures from the ego-network of a } \\
\text { stakeholder and using them to predict the network topology of another } \\
\text { stakeholder with an exponential random graph model (ERGM). If the } \\
\text { prediction was successful the two stakeholders were assigned the same } \\
\text { role. }\end{array}$} & \multirow[t]{2}{*}{$\begin{array}{l}\text { Box-Steffensmeier } \\
\text { et al. (2018) }\end{array}$} \\
\hline $\begin{array}{l}\text { Peripheral specialist only cooperates with other interest groups whose } \\
\text { goals are as specialised as hers }\end{array}$ & & & \\
\hline Achievement players wants to become powerful in the game. & \multirow{2}{*}{ Online game } & \multirow{2}{*}{$\begin{array}{l}\text { connducting a factor analysis based on players' likert scale scores on } \\
\text { survey questions such as 'I like to feel powerful in the game.. }\end{array}$} & \multirow{2}{*}{ Yee (2006) } \\
\hline $\begin{array}{l}\text { Manipulation players manipulates other players for her personal gains } \\
\text { (e.g., deceiving). }\end{array}$ & & & \\
\hline Free-loader uses other players to advance in the game. & Online game & $\begin{array}{l}\text { applying a block model to shared interaction types of players and } \\
\text { analysing ego-network structures within and relations between blocks. }\end{array}$ & $\begin{array}{l}\text { Ang and Zaphiris } \\
(2010)\end{array}$ \\
\hline
\end{tabular}


Table 3: Mapping empirical roles onto the simple meta-role of the group supporter. The group supporter ensures that individuals comply to group norms and are involved in the community, gets task-related activities moving, and initiates contact by introducing individuals to one another

\begin{tabular}{|c|c|c|c|}
\hline \multirow{2}{*}{$\begin{array}{ll} & \text { This approach } \\
\text { Role } & \\
\end{array}$} & \multicolumn{3}{|c|}{ Previous work } \\
\hline & Research context & Classify roles by ... & Author \\
\hline \multicolumn{4}{|l|}{ Qualitative } \\
\hline Motivator keeps conversations going. & \multirow[t]{2}{*}{$\begin{array}{l}\text { Online discussion } \\
\text { forum }\end{array}$} & \multirow{2}{*}{$\begin{array}{l}\text { conceptually pre-defining roles of users in an online discussion forum } \\
\text { and manually comparing them with selected topological network mea- } \\
\text { sures of users from the communication network of all users }\end{array}$} & \multirow[t]{2}{*}{$\begin{array}{l}\text { Nolker and Zhou } \\
(2005)\end{array}$} \\
\hline Leader spreads knowledge and works towards a cohesive community. & & & \\
\hline Low-volume replier answers other individuals's questions. & $\begin{array}{l}\text { Online discussion } \\
\text { forum }\end{array}$ & $\begin{array}{l}\text { manually grouping users based on likert scale scores of a survey (e.g., 'I } \\
\text { often provide answers to other individuals' questions') and correlating } \\
\text { scores within a group with log measures of users' platform behaviour } \\
\text { (e.g., time spent on platform). }\end{array}$ & $\underset{(2005)}{\text { Brush et al. }}$ \\
\hline Answer person provides advice to others. & $\begin{array}{l}\text { Online discussion } \\
\text { forum }\end{array}$ & $\begin{array}{l}\text { visually inspecting descriptive statistics of users' posting activities, such } \\
\text { as the number of sent messages. }\end{array}$ & $\begin{array}{l}\text { Combs Turner } \\
\text { et al. }(2005)\end{array}$ \\
\hline Answer person answers other individuals's questions. & \multirow[t]{2}{*}{$\begin{array}{l}\text { Online discussion } \\
\text { forum }\end{array}$} & \multirow{2}{*}{$\begin{array}{l}\text { selecting four distinct sub-forums with distinct interaction cultures, } \\
\text { respectively, and visually comparing the degree distributions of the } \\
\text { communication networks from the forums. }\end{array}$} & \multirow[t]{2}{*}{ D. Fisher (2005) } \\
\hline Social supporter helps new users and keeps in touch with active users. & & & \\
\hline $\begin{array}{l}\text { Mentor helps other users and enjoys a good reputation in the commu- } \\
\text { nity. }\end{array}$ & \multirow[t]{3}{*}{$\begin{array}{l}\text { Online discussion } \\
\text { forum }\end{array}$} & \multirow{3}{*}{$\begin{array}{l}\text { observing discussions in pre-selected forums, asking comprehension } \\
\text { questions to the forum's manager, running focus groups with members } \\
\text { of the forum, and visulally analysing temporal frequency plots showing } \\
\text { the number of initiated and answered messages per user and day. }\end{array}$} & \multirow{3}{*}{$\begin{array}{l}\text { Combs Turner } \\
\text { and K.E. Fisher } \\
(2006)\end{array}$} \\
\hline $\begin{array}{l}\text { Manager ensures that individuals adhere to the rules and norms of the } \\
\text { community. }\end{array}$ & & & \\
\hline Mogul answers complex questions and helps when problems escalate. & & & \\
\hline Answer person anwers other individuals's questions. & $\begin{array}{l}\text { Online discussion } \\
\text { forum }\end{array}$ & $\begin{array}{l}\text { using a logit regression to infer the answer person role (based on hand- } \\
\text { coded messages) from user's operationalised ego-networks, degree- and } \\
\text { temporal frequency distributions. }\end{array}$ & $\begin{array}{l}\text { Welser et al. } \\
(2007)\end{array}$ \\
\hline Answer person anwers other individuals's questions. & \multirow{4}{*}{$\begin{array}{l}\text { Online discussion } \\
\text { forum }\end{array}$} & \multirow{4}{*}{$\begin{array}{l}\text { handcoding user messages and visually relating the resulting content } \\
\text { groups with structural properties of users' ego-networks (e.g., density } \\
\text { of edges in periphery) extracted from the communication network of all } \\
\text { users. }\end{array}$} & \multirow{4}{*}{$\begin{array}{l}\text { Gleave et al. } \\
(2009)\end{array}$} \\
\hline $\begin{array}{l}\text { Discussion catalyst initiates new discussion threads that other individu- } \\
\text { als pick up on. }\end{array}$ & & & \\
\hline $\begin{array}{l}\text { Substansive expert resolves disputes and contributes to content-related } \\
\text { discussions. }\end{array}$ & & & \\
\hline Technical editor enforces formatting standards. & & & \\
\hline $\begin{array}{l}\text { Substansive expert resolves content-related disputes and contributes } \\
\text { knowledge to the discussion. }\end{array}$ & \multirow[t]{3}{*}{$\begin{array}{l}\text { Online discussion } \\
\text { forum }\end{array}$} & \multirow{3}{*}{$\begin{array}{l}\text { using a linear regression to infer handcoded content groups of user mes- } \\
\text { sages (roles) from structural properties of users' ego-networks derived } \\
\text { from the communication network of users. }\end{array}$} & \multirow[t]{3}{*}{$\begin{array}{l}\text { Welser et al. } \\
(2011)\end{array}$} \\
\hline Technical editor enforces formatting standards. & & & \\
\hline $\begin{array}{l}\text { Counter vandalism editor sanctions users who do not comply to the } \\
\text { rules of the community. }\end{array}$ & & & \\
\hline $\begin{array}{l}\text { Facilitator keeps the debate moving by encouraging other users to par- } \\
\text { tipate and by solving problems. }\end{array}$ & $\begin{array}{l}\text { Online learning } \\
\text { forum }\end{array}$ & $\begin{array}{l}\text { manually coding users' messages along an extended version of Garrison } \\
\text { et al. (2000)'s coding dimensions of teaching, social, and cognitive. }\end{array}$ & $\begin{array}{l}\text { Waters and Gas- } \\
\text { son }(2005)\end{array}$ \\
\hline
\end{tabular}


Table 3: Mapping empirical roles onto the simple meta-role of the group supporter (cont).

\begin{tabular}{|c|c|c|c|}
\hline This approach & & Previous work & \\
\hline Role & Research context & Classify roles by ... & Author \\
\hline \multicolumn{4}{|l|}{ Qualitative cont. } \\
\hline \multicolumn{4}{|l|}{ Seeker gets the discussion going by asking questions. } \\
\hline $\begin{array}{l}\text { Governor ensures that users comply to the rules and norms of the com- } \\
\text { munity. }\end{array}$ & \multirow[t]{5}{*}{$\begin{array}{l}\text { Online discussion } \\
\text { forum }\end{array}$} & \multirow[t]{5}{*}{$\begin{array}{l}\text { manually coding users' messages and user interviews along Miles et al. } \\
\text { (2019) theory building process. }\end{array}$} & \multirow[t]{5}{*}{ Seraj (2012) } \\
\hline Educator shares her knowledge with the community. & & & \\
\hline $\begin{array}{l}\text { Challenger questions the provided information and provides alternative } \\
\text { perspectives. }\end{array}$ & & & \\
\hline $\begin{array}{l}\text { Appraiser recognizes the contribution of other users and encourages } \\
\text { them to get further involved in the community. }\end{array}$ & & & \\
\hline Innovator provides an alternative perspective. & & & \\
\hline Pillar engages in group activities to get the collaborative task done. & \multirow{2}{*}{$\begin{array}{l}\text { Online learning } \\
\text { forum }\end{array}$} & \multirow{2}{*}{$\begin{array}{l}\text { pre-defining roles based on a literature review on computer-supported } \\
\text { collaborative learning environments and matching these roles to hand- } \\
\text { coded user messages. }\end{array}$} & \multirow{2}{*}{$\begin{array}{l}\text { Strijbos and } \\
\text { Weinberger } \\
(2010)\end{array}$} \\
\hline $\begin{array}{l}\text { Hanger-on aims to contribute to the collaborative tasks but does not } \\
\text { manage to live up to her own expectations. }\end{array}$ & & & \\
\hline \multicolumn{4}{|l|}{ Quantitative } \\
\hline $\begin{array}{l}\text { Core member extensively contributes knowledge to and retrieves knowl- } \\
\text { edge from the community. }\end{array}$ & \multirow[t]{2}{*}{$\begin{array}{l}\text { Online discussion } \\
\text { forum }\end{array}$} & \multirow{2}{*}{$\begin{array}{l}\text { applying k-means clustering to users' survey scores about usage of dis- } \\
\text { cussion forum (e.g., amount of supplied information to discussion) and } \\
\text { comparing resulting clusters with an ANOVA. }\end{array}$} & \multirow[t]{2}{*}{$\begin{array}{l}\text { de Valck et al. } \\
(2009)\end{array}$} \\
\hline $\begin{array}{l}\text { Informationalist moderately contributes knowledge to and retrieves } \\
\text { knowledge from the community. }\end{array}$ & & & \\
\hline $\begin{array}{l}\text { Moderating supporter provides support to other users and has a strong } \\
\text { interest in the community. }\end{array}$ & \multirow[t]{3}{*}{$\begin{array}{l}\text { Online discussion } \\
\text { forum }\end{array}$} & \multirow{3}{*}{$\begin{array}{l}\text { handcoding user messages along five dimensions, including empathetic } \\
\text { content and user-centered content and comparing the resulting user } \\
\text { groups to regular equivalent users computed on the communication net- } \\
\text { work with the Continuous REGE algorithm of the UCINET software. }\end{array}$} & \multirow[t]{3}{*}{ Pfeil et al. (2011) } \\
\hline Central supporter provides and receives support to/from other users. & & & \\
\hline $\begin{array}{l}\text { Technical expert provides support to other users but does not receive } \\
\text { much support back in return. }\end{array}$ & & & \\
\hline Master provides a lot of useful postings for other users. & $\begin{array}{l}\text { Online discussion } \\
\text { forum }\end{array}$ & $\begin{array}{l}\text { applying k-means and hierarchical clustering to users' topological mea- } \\
\text { sures of their communication network (e.g., number of sent messages, } \\
\text { i.e. out-degree) and users' feature of platform usage (e.g., number of } \\
\text { posted ideas), and comparing resulting clusters with an ANOVA. }\end{array}$ & $\begin{array}{l}\text { Füller et al. } \\
(2014)\end{array}$ \\
\hline Gatekeeper ensures that the group identity and values are in place. & \multirow{3}{*}{$\begin{array}{l}\text { Online discussion } \\
\text { forum }\end{array}$} & \multirow{3}{*}{$\begin{array}{l}\text { handcoding user messages and visually relating the resulting content } \\
\text { groups to descriptive statistics of users' activity features (e.g., time } \\
\text { spent in the discussion group) and to structural properties of users' ego- } \\
\text { networks (e.g., number of sent messages (out-degree)) extracted from } \\
\text { the communication network of all users. }\end{array}$} & \multirow{3}{*}{$\begin{array}{l}\text { Benamar et al. } \\
(2017)\end{array}$} \\
\hline Mentor helps other users with the technical functionalities of the forum. & & & \\
\hline $\begin{array}{l}\text { Product ambassador shares information to improve other users' knowl- } \\
\text { edge. }\end{array}$ & & & \\
\hline Coordinator mediates coalitions between others. & $\begin{array}{l}\text { Dyadic communi- } \\
\text { cation }\end{array}$ & $\begin{array}{l}\text { extracting topological network measures from the ego-network of a } \\
\text { stakeholder and using them to predict the network topology of another } \\
\text { stakeholder with an exponential random graph model (ERGM). If the } \\
\text { prediction was successful the two stakeholders were assigned the same } \\
\text { role. }\end{array}$ & $\begin{array}{l}\text { Box-Steffensmeier } \\
\text { et al. }(2018)\end{array}$ \\
\hline $\begin{array}{l}\text { Knowledge-player helps other players and encourages the group to do } \\
\text { so, too. }\end{array}$ & Online game & $\begin{array}{l}\text { applying a block model to shared interaction types of players and } \\
\text { analysing ego-network structures within and relations between blocks. }\end{array}$ & $\begin{array}{l}\text { Ang and Zaphiris } \\
(2010)\end{array}$ \\
\hline
\end{tabular}




\section{Constructing a new theory of social roles}

\subsection{Cluster extend the simple approach: nine-meta roles emerge}

What is missing from the previous simple approach are clusters. We embedded communication roles from previous empirical research into the three simple meta-roles defined along two dimensions, strategicness and type-of strategy. However, this approach does not account for the complex structure of networks. Clusters separate the global communication into several interconnected local structures with distinct interactions within and between them.

Since these interaction structures have a large impact on social life in terms of facilitating social learning (Henrich \& McElreath, 2003), resource allocation (Sapolsky, 2004), and boosting productivity and motivation (Halevy et al., 2011; Koski et al., 2015), they also affect the roles individuals fulfill.

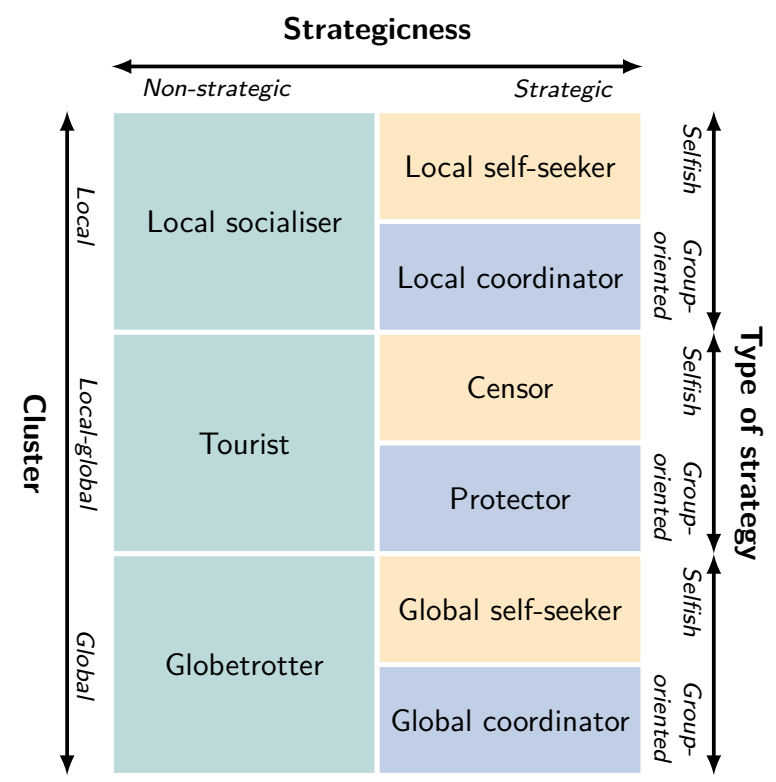

Figure 5: The complex approach to provide a theory of social roles accounting for network structures. Nine meta-roles are circumscribed along three dimensions. The nine meta-roles are: local socialiser, tourist, globetrotter, local self-seeker, local coordinator, censor, protector, global self-seeker, global coordinator. The dimensions are strategicness, type of strategy, and cluster. Each dimension is defined by ordinal or nominal categories and each meta-role is placed into one of these categories per dimension. For example, the green meta-roles are categorised as non-strategic along the strategicness dimension whereas the yellow and blue meta-roles are categorised as strategic. The cluster dimension indicates whether interactions occur within clusters (local), between clusters (local-global), or within the whole network (global). 
In order to account for clusters in our theory, we extend the simple approach from Figure 4 with a third dimension for clusters. Since this extended approach incorporates complex network structures, the clusters, we refer to it as 'complex approach' and distinguish it from the previously defined simple approach in Figure 6. Adding the cluster dimension increases the number of meta-roles from three in the simple approach to nine in the complex one (Fig. 5). We remind ourselves that the simple meta-roles, socialiser, self-seeker, and group supporter, were circumscribed along two dimensions. Strategicness distinguishes whether someone acts in a determined (strategic) or spontaneous (non-strategic) way. If the person is strategic her type of strategy indicates whether she aims to achieve her own goals (selfish) or the goals of the group (group-oriented).

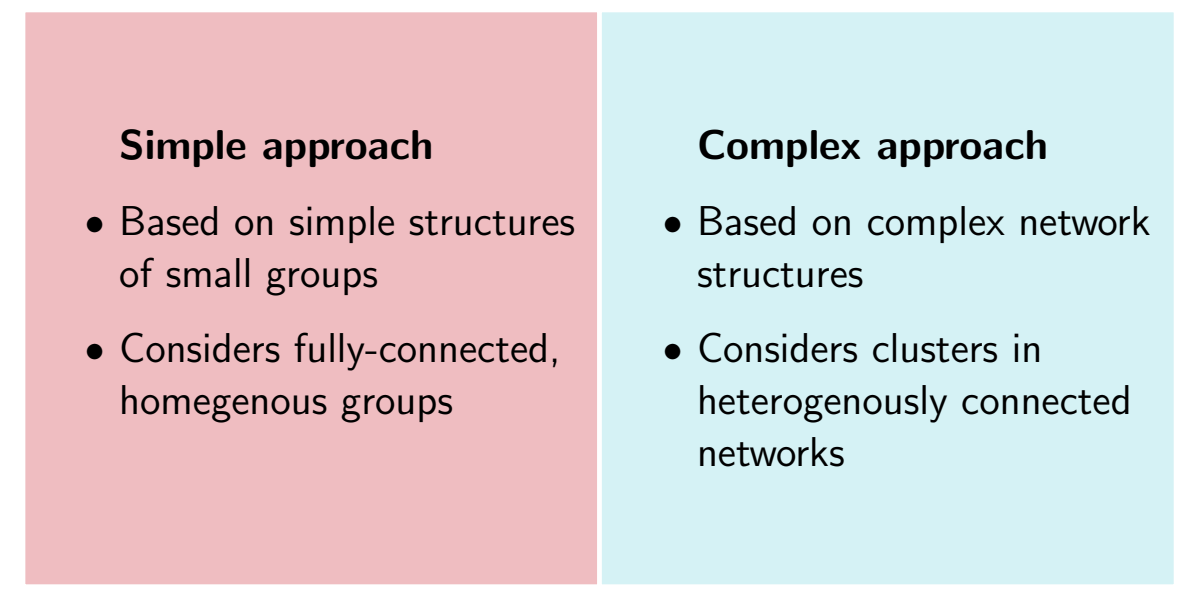

Figure 6: Comparing the simple and the complex approach. The simple approach takes a small group perspective. It represents the first step towards building our theory of social roles. The complex approach extends the simple one with a network perspective. It represents our developed theory of social roles

The new third dimension accounts for the grouping of the global communication network into sub structures. The three cluster levels local, local-global, and global indicate how the communication behaviour of a person is embedded into the overall network. In the local case, communication is mainly restricted to the cluster the person belongs to. In the local-global case, the person is still strongly embedded within her cluster but increasingly bridges to other clusters and communicates with the individuals there. In the global case, the person is only weakly embedded in a cluster and communicates with many other parts of the network. For each of the three meta-roles in the simple approach (Fig. 4) three new meta-roles are created in the complex approach, one for each level of the cluster dimension (Fig. 5). 
Socialiser The socialiser in the simple approach is split into three non-strategic roles in the complex approach: local socialiser, tourist and globetrotter. Like the simple socialiser, these roles all communicate for the sake of fun without pursuing a planned goal. They just want to stay in touch with others. Whereas the local socialiser mainly communicates with individuals from her own cluster, the tourist also communicates with individuals from different clusters. The globetrotter cannot be clearly assigned to a cluster and communicates with individuals from many clusters.

Self-seeker The self-seeker in the simple approach is split into three strategic, selfish roles in the complex approach: local self-seeker, censor and global self-seeker. Like the simple self-seeker, all exploit information flow for their own interest. They only focus on pursuing their own goals rather than group-related ones. Whereas the local self-seeker mainly communicates with individuals from her own cluster, the censor also communicates with individuals from different clusters. The censor also withholds external information from her own cluster and cluster members may be forced to get external information via the censor rather than directly communicating with other clusters. The global self-seeker cannot be clearly assigned to a cluster and communicates with individuals from many clusters.

Group supporter The group supporter in the simple framework is split into three strategic, group-oriented roles in the complex approach: local coordinator, protector and global coordinator. Like the simple group supporter, all direct information flow to pursue a group goal. Whereas the local coordinator mainly communicates with individuals from her own cluster, the protector also communicates with individuals from different clusters. The protector also amplifies external information so that many members of her own cluster can access it and also protects her community against harmful external influences. The global coordinator cannot be clearly assigned to a cluster and communicates with individuals from many clusters.

\subsection{Clusters in existing empirical roles}

Existing empirical research already hints at these local-global relations but does not incorporate them explicitly into the role detection analysis. For example, authors detected roles whose meaning is based on interactions between different local groups, which are inbuilt into the architecture of the global network by some members of the network. These local groups are not external to the network, like labels (Fig. 2), yet they are not fully emergent like clusters because only some members of the network can affect the formation of local groups, such as adding new discussion groups to a forum. The jumpy questioner switches between discussion groups of one news forum (Combs Turner et al., 2005). The gatekeeper controls the flow of information between the inside and the out- 
side of a discussion group (Benamar et al., 2017). The leader spreads knowledge across different threads of one discussion group (Nolker \& Zhou, 2005). In online gaming, the explorer switches between the known gaming world and new settings (Bartle, 1996). The role of escapism points to the distinction between the gaming world and the real one (Yee, 2006).

However, many previous authors were unable to detect roles which mirror the cluster structure of the network because authors often restricted their analysis to interactions within local groups rather than also considering those between local groups. For instance, individual discussion groups of one forum were analysed in isolation and assigned individual roles (D. Fisher, 2005; Gleave et al., 2009; Welser et al., 2011). Roles were defined by the local communication patterns of individuals (ego-network) and analysed in isolation without considering interdependencies (Box-Steffensmeier et al., 2018).

Besides considering inbuilt local groups, some studies also hint at the bottom-up attribute of clusters which emerge from the interaction dynamics. For example, roles distinguish between active users who send and receive messages and passive users who only receive messages. Interestingly, many of the reviewed roles which could not be matched into the simple approach (Appendix D: undefined roles) are either highly case-specific or can be explained with an active-passive clustering in the complex approach. Ang and Zaphiris (2010) distinguish the active roles of socialiser, free-loader, and knowledge player from the passive one of the newbie. Golder and Donath (2004)'s active roles are the celebrity, the flamer, the troll, and the ranter, whereas the passive roles are the lurker and the newbie. Brush et al. (2005) contrast the active roles of questioner, low-volume replier with the passive ones of reader, disengaged observed, and key contributor. Pfeil et al. (2011) contrasts the active roles of active member, passive member, moderating supporter, central supporter, and technical expert with the passive role of the visitor. Füller et al. (2014) detected the active roles of socialiser, and master as well as the passive ones of passive, idea generator, and efficient contributor. Moreover, other emergent clusters developed on the basis of differences in reputation (Combs Turner et al., 2005), payed membership fee, and time spent in premium parts of the forum (Seraj, 2012).

\subsection{How to apply this theory in practice}

Although previous empirical research has implicitly hinted at cluster-based roles, we argue that this link must be made explicit by applying our theory to systematically advance insights into social behaviour. But how should our theory be applied in practice? We provide suggestions for three areas of application: operationalisation, falsification, and further development of the theory.

Operationalising our theory means translating abstract concepts such as clusters into quantifiable measures and incorporating them into the analysis. We can account for these clusters in a bottom-up or top-down manner by either considering clusters that 
emerge from interactions in the network (clustering in Figure 2) or using external labels that group similar individuals (labels in Figure 2). For bottom-up clusters we may use algorithms for community detection from network research (Fortunato \& Hric, 2016). Since community detection algorithms differ in the way they define communities it is important to select an algorithm that matches the theoretical and conceptual definition of the to-be-detected clusters. The choice of the algorithm should be motivated explicitly.

Falsifying our theory means checking if empirical studies detect the proposed metaroles, given that these studies account for network clusters. The theory is falsified if empirical studies do not yield the expected meta-roles and supported in the opposite case. If we support the theory, the theory guides the design of future empirical studies by showing that accounting for clusters in networks substantially improves role detection. Once sufficient support for the theory is established it can be used to validate empirical studies. Importantly, finding support for this theory does not imply that all nine-meta roles are always found in the empirical analyses. Depending on the data, only a subset of the meta-roles may be found. However, each empirically detected role should always match one of the meta-roles. If additional roles are found that cannot be mapped to one of the meta-roles the theory is falsified and has to be adapted.

Further development of the theory means feeding empirical results back into the theory to differentiate it. For example, by comparing different versions of operationalisation and validation the scope of the theory can be refined. This requires a systematic method to compare empirical applications of a theory which will be necessary to develop but is beyond the scope of this article.

The suggested applications of operationalisation, falsification, and further development of the theory show that the development of this theory for social roles is an open process which requires a feedback loop between empirical and theoretical research. In summary, we need a theory for social roles to account for communication in large networks, to generalise empirical findings beyond individual case studies, and to understand human interactions.

\section{Conclusion}

Empirical research on role detection in large social networks has not been sufficiently grounded in theory, and the lack of testable theories undermines empirical role detection in general.

This article encourages researchers studying empirical role detection to be more theoretically engaged, adapt existing frameworks to modern settings of interest (individuals no longer only communicate in small groups), and actively validate empirical findings with theories. More theoretical engagement facilitates comparisons of different studies and counteracts blindly looking for meaningful patterns in the data which often leads 
to mistaking random effects for true ones.

This article develops a theory of communication roles in large social networks based on similarities between detected roles from previous empirical research and a novel cluster dimension which captures the inherent local-global relation in these networks. The theory embeds nine roles along three dimensions which describe the type and range of individuals' interactions. Strategicness indicates whether the person works towards a goal (strategic) or interacts without specific planning (non-strategic). The type of strategy indicates whether that goal is selfish or group-oriented. The cluster dimension indicates to what extent interactions are embedded locally or globally in the system. In the local case, the person restricts her interactions to her cluster. In the local-global case she is still part of a cluster but also interacts with individuals in different clusters. In the global case, the person cannot be clearly assigned to a cluster and interacts with many different parts of the system.

The non-strategic roles are the local socialiser, the tourist, and the globetrotter who communicate just for fun without pursuing a particular goal. The selfish roles are the local self-seeker, the censor, and the global self-seeker who control information flow to accomplish selfish goals. In contrast, the group-oriented roles, local coordinator, protector, and global coordinator, control information flow to accomplish group goals. Specifically, the censor withholds external information from her own cluster whereas the protector amplifies external information so that many members of her cluster can access it.

Role researchers should debate this theory, the usefulness of conceptualising roles along the proposed three dimensions, and how to operationalise and validate the theory. Testable theories should accompany empirical role detection research to generate hypotheses and validate results.

However, theories can only inform empirical research if they account for important characteristics of the network under study, such as clusters in large communication networks. This is why existing theories need to be updated regularly, which we attempt to do in this article. Applying and further developing our theory of communication roles will help researchers to find similarities in their detected roles and prevent them from reinventing the wheel in every new study.

\section{Summary points}

- There has been a lack of theory-driven empirical research on role detection.

- Previous empirical research has conducted isolated case studies and did not account for systematic complex structures in networks.

- This theory is based on grouping similar roles from previous studies into metaroles which are conceptualised along two dimensions: strategicness and type of strategy. 
- This theory is extended by the clustering dimension which accounts for complex structures in networks.

- This theory yields nine meta-roles: The non-strategic ones of local socialiser, tourist and globetrotter. The strategic, selfish ones of local self-seeker, censor, and global self-seeker. The strategic, group-oriented ones of local coordinator, protector, and global coordinator.

- To assess our theory, empirical research has to test how useful the embedding of roles along the proposed three dimensions is to explain social behaviour.

\section{Future issues}

- The role detection community should debate the proposed schema of conceptualising meta-roles along three dimensions, and how to classify detected roles from previous empirical studies into these meta-roles.

- Empirical research should discuss how to measure roles in a theory-driven analysis and ensure that the roles can still be interpreted.

- There is a need to establish systematic methods for theory operationalising and validation to compare different empirical applications of the theory.

\section{Disclosure statement}

The authors are not aware of any affiliations, memberships, funding, or financial holdings that might be perceived as affecting the objectivity of this article.

\section{Acknowledgements}

The authors thank Laurence Brandenberger for valuable suggestions. 


\section{References}

Ang, C.S. \& Zaphiris, P., 2010. Social roles of players in mmorpg guilds: A social network analytic perspective. Information communication and society [Online], 13(4), pp.592-614. Available from: https://doi.org/10.1080/13691180903266952.

Arrow, H., 1997. Stability, bistability, and instability in small group influence patterns. Journal of personality and social psychology [Online], 72(1), pp.75-85. Available from: https://doi. org/10.4324/9780203647585.

Bales, R.F., 1950. Interaction process analysis; a method for the study of small groups. Cambridge, MA: Addison-Wesley.

Bartle, R., 1996. Hearts, Clubs, Diamonds, Spades: Players Who Suit Muds. Journal of mud research, 1(1), pp.1-19.

Belbin, M.R., 2010. Management Teams: Why They Succeed or Fail. 3rd. Butterworth Heinemann.

Benamar, L., Balagué, C., \& Ghassany, M., 2017. The Identification and Influence of Social Roles in a Social Media Product Community. Journal of computer-mediated communication [Online], 22(6), pp.337-362. Available from: https://doi.org/10.1111/jcc4.12195.

Benne, K.D. \& Sheats, P., 1948. Functional Roles of Group Members. Journal of social issues [Online], 4(2), pp.41-49. Available from: https://doi.org/10.1111/j.1540-4560.1948. tb01783.x.

Biddle, B., 1986. Recent Developments in Role Theory. Annual review of sociology [Online], 12(1), pp.67-92. Available from: https://doi.org/10.1146/annurev.soc.12.1.67.

Blumer, H., 1969. Symbolic Interactionism: Perspective and Method. 1st. Englewood Cliffs: Prentice-Hall.

Borgatti, S.P. \& Everett, M.G., 1989. The class of all regular equivalences: Algebraic structure and computation. Social networks [Online], 11(1), pp.65-88. Available from: https://doi . org/10.1016/0378-8733(89)90018-X.

Bottero, W., 2005. Stratification: Social division and inequality. London: Routledge.

Box-Steffensmeier, J.M., Campbell, B.W., Christenson, D.P., \& Navabi, Z., 2018. Role analysis using the ego-ERGM: A look at environmental interest group coalitions. Social networks [Online], 52, pp.213-227. Available from: https://doi.org/10.1016/j.socnet.2017.08.004.

Brush, A.J., Wang, X., Turner, T.C., \& Smith, M.A., 2005. Assessing differential usage of usenet social accounting meta-data. Chi 2005: technology, safety, community: conference proceedings - conference on human factors in computing systems [Online], pp.889-898. Available from: https://doi.org/10.1145/1054972.1055097.

Burt, R.S., 1976. Positions in networks. Social forces [Online], 55(1), pp.93-122. Available from: https://doi.org/10.1093/sf/55.1.93.

Burt, R.S., 1982. Toward a Structural Theory of Action: Network Models of Social Structure, Perception and Action [Online]. London: Academic Press. Available from: https://doi.org/ 10.1016/C2009-0-21953-2.

Coleman, J., 1998. Foundations of Social Theory. Cambridge, MA: Harvard University Press.

Combs Turner, T. \& Fisher, K.E., 2006. The Impact of Social Types within Information Communities : Findings from Technical Newsgroups. Proceedings of the 39th annual hawaii in- 
ternational conference on system sciences (hicss'06) [Online], pp.135b-135b. Available from: https://doi.org/10.1109/HICSS.2006.471.

Combs Turner, T., Smith, M.A., Fisher, D., \& Welser, H.T., 2005. Picturing Usenet: Mapping Computer-Mediated Collective Action. Journal of computer-mediated communication [Online], 10(4). Available from: https://doi.org/https://doi.org/10.1111/j.1083-6101. 2005. tb00270.x.

Costa, G. \& Ortale, R., 2012. A bayesian hierarchical approach for exploratory analysis of communities and roles in social networks. Proceedings of the 2012 ieee/acm international conference on advances in social networks analysis and mining, asonam 2012 [Online]. IEEE, pp.194-201. Available from: https://doi.org/10.1109/ASONAM. 2012.42.

de Sola Pool, I. \& Kochen, M., 1978. Contacts and influence. Social networks [Online], 1(1), pp.5-51. Available from: https://doi.org/10.1016/0378-8733(78)90011-4.

de Valck, K., Bruggen, G.H. van, \& Wierenga, B., 2009. Virtual communities: A marketing perspective. Decision support systems [Online], 47(3), pp.185-203. Available from: https: //doi.org/10.1016/j.dss.2009.02.008.

De Wever, B., Schellens, T., Van Keer, H., \& Valcke, M., 2008. Structuring Asynchronous Discussion Groups by Introducing Roles: Do Students Act in Line With Assigned Roles ? Small group research [Online], 39(6), pp.770-794. Available from: https ://doi .org/10.1177/ 1046496408323227.

DeVito, J.A., 2014. Essentials of Human Communication. 8th. New Jersey: Pearson.

Dunbar, R.I.M., 1992. Neocortex size as a constraint size in primates on group ecologically. Journal of human evolution [Online], 20, pp.469-493. Available from: https : //doi.org/ https://doi.org/10.1016/0047-2484(92)90081-J.

Feld, S.L., 1981. The Focused Organization of Social Ties. American journal of sociology [Online], 86(5), pp.1015-1035. Available from: https://doi.org/10.1086/227352.

Fisher, D., 2005. Using egocentric networks to understand communication. Ieee internet computing [Online], 9(5), pp.20-28. Available from: https://doi.org/10.1109/MIC.2005.114.

Fortunato, S. \& Hric, D., 2016. Community detection in networks: A user guide. Physics reports [Online], 659, pp.1-44. arXiv: 1608.00163. Available from: https://doi.org/10.1016/j . physrep. 2016.09.002.

Füller, J., Hutter, K., Hautz, J., \& Matzler, K., 2014. User roles and contributions in innovationcontest communities. Journal of management information systems [Online], 31(1), pp.273-308. Available from: https://doi.org/10.2753/MIS0742-1222310111.

Garrison, D., Anderson, T., \& Archer, W., 2000. Critical Inquiry in a Text-Based Environment. The internet and higher education, 2(2), pp.87-105. arXiv: 1931-7913.

Garrison, D., Anderson, T., \& Archer, W., 2001. Critical thinking, cognitive presence, and computer conferencing in distance education. International journal of phytoremediation [Online], 21(1), pp.7-23. Available from: https://doi.org/10.1080/08923640109527071.

Gersick, C.T., 1991. Revolutionary Change Theories : A Multilevel Exploration of the Punctuated Equilibrium Paradigm. The academy of management review [Online], 16(1), pp.10-36. Available from: https://doi.org/10.2307/258605.

Giardini, F. \& Wittek, R.P., 2019. Silence is golden. Six reasons inhibiting the spread of thirdparty gossip. Frontiers in psychology [Online], 10, pp.11-20. Available from: https://doi . org/10.3389/fpsyg. 2019.01120. 
Giddens, A. \& Sutton, P.W., 2017. Sociology [Online]. 8th. London: Polity Press. Available from: https://www . wiley.com/en-nl/Sociology\%2C+8th+Edition-p-9780745696683.

Gleave, E., Welser, H.T., Lento, T.M., \& Smith, M.A., 2009. A conceptual and operational definition of 'social role' in online community. Proceedings of the 42nd annual hawaii international conference on system sciences, hicss [Online], pp.1-11. Available from: https: //doi.org/10.1109/HICSS.2009.6.

Golder, S. \& Donath, J., 2004. Social roles in electronic communities. Internet research, 5, pp.1922.

Gross, N., Mason, W.S., \& McEachern, A.W., 1958. Explorations in role analysis: Studies of the school superintendency role [Online]. New York: Wiley. Available from: https://psycnet . apa.org/record/1958-02148-000.

Halevy, N., Chou, E.Y., \& Galisnky, A.D., 2011. A functional model of hierarchy: Why, how, and when vertical differentiation enhances group performance. Organizational psychology review [Online], 1(1), pp.32-52. Available from: https://doi.org/10.1177/2041386610380991.

Henderson, K., Gallagher, B., Eliassi-rad, T., \& Berkeley, U.C., 2012. RolX: Structural Role Extraction \& Mining in Large Graphs. Proceedings of the 18th acm sigkdd international conference on knowledge discovery and data mining [Online], pp.1231-1239. Available from: https: //doi.org/10.1145/2339530.2339723.

Henrich, J. \& McElreath, R., 2003. The Evolution of Cultural Evolution. Evolutionary anthropology [Online], 12(3), pp.123-135. Available from: https://doi.org/10.1002/evan.10110.

Hofstra, B., Corten, R., Tubergen, F. van, \& Ellison, N.B., 2017. Sources of Segregation in Social Networks: A Novel Approach Using Facebook. Vol. 82, 3, pp.625-656. Available from: https://doi.org/10.1177/0003122417705656.

Hornsey, M.J. \& Hogg, M.A., 2000. Subgroup relations: A comparison of mutual intergroup differentiation and common ingroup identity models of prejudice reduction. Personality and social psychology bulletin [Online], 26(2), pp.242-256. Available from: https://doi.org/10. $1177 / 0146167200264010$.

Hymes, D., 1974. Foundations in Sociolinguistics: An Ethnographic Approach. Philadelphia, PA: University of Pennsylvania Press.

Johnson, S., Domínguez-García, V., \& Muñoz, M.A., 2013. Factors Determining Nestedness in Complex Networks. Plos one [Online], 8(9). Ed. by Y. Moreno, e74025. Available from: https : //doi.org/10.1371/journal.pone.0074025.

Jones, E.E. \& Pittman, T.S., 1982. Toward a general theory of strategic self-presentation. In: J. Suis, ed. Psychological perspectives on the self. Hillsdale: Lawrence Erlbaum, pp.231-262.

Kahn, R.L., Wolfe, D.M., Quinn, R.P., Snoek, J.D., \& Rosenthal, R.A., 1964. Organizational stress: Studies in role conflict and ambiguity. New York: Wiley.

Karrer, B. \& Newman, M.E., 2011. Stochastic blockmodels and community structure in networks. Physical review e - statistical, nonlinear, and soft matter physics [Online], 83(1), pp.1-10. arXiv: 1008.3926. Available from: https://doi.org/10.1103/PhysRevE.83.016107.

Keijzer, M.A., Mäs, M., \& Flache, A., 2018. Communication in Online Social Networks Fosters Cultural Isolation. Complexity [Online], pp.1-18. Available from: https://doi.org/10.1155/ $2018 / 9502872$. 
Koski, J.E., Xie, H., \& Olson, I.R., 2015. Understanding social hierarchies: The neural and psychological foundations of status perception. Social neuroscience [Online], 10(5), pp.527550. Available from: https://doi.org/10.1080/17470919.2015.1013223.

Kozinets, R.V., 1999. E-tribalized marketing?: The strategic implications of virtual communities of consumption. European management journal [Online], 17(3), pp.252-264. Available from: https://doi.org/10.1016/S0263-2373(99)00004-3.

Krackhardt, D. \& Stern, R.T., 1988. Informal Networks and Organizational Crises : An Experimental Simulation. Social psychology quarterly [Online], 51(2), pp.123-140. Available from: https://doi.org/10.2307/2786835.

Lazarsfeld, P. \& Merton, R.., 1954. Friendship as social process: a substantive and methodological analysis. In: M. Berger, A. Theodore, \& C.H. Page, eds. Freedom and control of modern society. New York: Macmillan, pp.18-66.

Linton, R., 1936. The study of man: an introduction. New York: Appleton-Century.

Macionis, J.J., 2017. Sociology. 16th. Harlow: Pearson.

Marx, K., 1859. Zur Kritik der politischen Ökonomie. Franz Duncker.

McPherson, M., Smith-lovin, L., \& Cook, J.M., 2001. Birds of a feather: Homophily in Social Networks. Annual review of sociology [Online], 27(1), pp.415-444. Available from: https: //doi.org/10.1146/annurev.soc.27.1.415.

Mead, G.H., 1934. Mind, Self and Society from the Standpoint of a Social Behaviorist. Ed. by C.W. Morris. Chicago: Chicago University Press.

Miles, M.B., Huberman, A.M., \& Saldana, J., 2019. Qualitative Data Analysis: A Methods Sourcebook. 4th. London: Sage.

Miritello, G., Lara, R., Cebrian, M., \& Moro, E., 2013a. Limited communication capacity unveils strategies for human interaction. Scientific reports [Online], 3, pp.1-7. arXiv: 1304.1979. Available from: https://doi.org/10.1038/srep01950.

Miritello, G., Moro, E., Lara, R., Martínez-López, R., Belchamber, J., Roberts, S.G., \& Dunbar, R.I., 2013b. Time as a limited resource: Communication strategy in mobile phone networks. Social networks [Online], 35(1), pp.89-95. arXiv: 1301.2464. Available from: https://doi. org $/ 10.1016 / j$. socnet. 2013.01.003.

Mitchell, M., 2006. Complex systems: Network thinking. Artificial intelligence [Online], 170(18), pp.1194-1212. Available from: https://doi.org/https ://doi.org/10.1016/j.artint. 2006.10.002.

Newman, M.E., 2006. Modularity and community structure in networks. Proceedings of the national academy of sciences of the united states of america [Online], 103(23), pp.8577-8582. arXiv: 0602124 [physics]. Available from: https://doi.org/10.1073/pnas.0601602103.

Nolker, R.D. \& Zhou, L., 2005. Social computing and weighting to identify member roles in online communities. Proceedings - $2005 \mathrm{ieee/wic/acm} \mathrm{internationalconference} \mathrm{on} \mathrm{web} \mathrm{intelligence,} \mathrm{wi}$ 2005 [Online], pp.87-93. Available from: https://doi.org/10.1109/WI.2005.134.

Parsons, T., 1951. The Social System. London: Routledge.

Pfeil, U., Svangstu, K., Ang, C.S., \& Zaphiris, P., 2011. Social Roles in an Online Support Community for Older People. International journal of human-computer interaction [Online], 27(4), pp.323-347. Available from: https://doi.org/10.1080/10447318.2011.540490. 
Putnam, R.D., 1995. Bowling Alone: America's Declining Social Capital. Journal of democracy [Online], 6(1), pp.65-78. Available from: https://doi.org/10.1353/jod.1995.0002.

Ribbens McCarthy, J. \& Edwards, R., 2011. Key Concepts in Family Studies. London: Sage.

Rickards, T. \& Moger, S., 2000. Creative Leadership Processes in Project Team Development: An Alternative to Tuckman's Stage Model. British journal of management [Online], 11(4), pp.273-283. Available from: https://doi.org/10.1111/1467-8551.00173.

Ruan, Y. \& Parthasarathy, S., 2014. Simultaneous detection of communities and roles from large networks. Cosn 2014 - proceedings of the 2014 acm conference on online social networks [Online], pp.203-214. Available from: https://doi.org/10.1145/2660460.2660482.

Sapolsky, R.M., 2004. Social status and health in humans and other animals. Annual review of anthropology [Online], 33, pp.393-418. Available from: https://doi.org/10.1146/annurev . anthro.33.070203.144000.

Saramäki, J., Leicht, E.A., López, E., Roberts, S.G., Reed-Tsochas, F., \& Dunbar, R.I., 2014. Persistence of social signatures in human communication. Proceedings of the national academy of sciences of the united states of america [Online], 111(3), pp.942-947. arXiv: 1204.5602. Available from: https://doi.org/10.1073/pnas.1308540110.

Savelsbergh, C., Gevers, J.M.P., Heijden, B.I.J.M. an der, \& Poell, R.F., 2012. Team Role Stress: Relationships With Team Learning and Performance in Project Teams. Group $\&$ organization management [Online], 37(1), pp.67-100. Available from: https://doi.org/10.1177/ 1059601111431977.

Savin-Williams, R.C., 1979. Dominance Hierarchies in Groups of Early Adolescents. Child development [Online], 50(4), pp.923-935. Available from: https://doi.org/10.2307/1129316.

Seraj, M., 2012. We Create, We Connect, We Respect, Therefore We Are: Intellectual, Social, and Cultural Value in Online Communities. Journal of interactive marketing [Online], 26(4), pp.209-222. Available from: https://doi.org/10.1016/j.intmar.2012.03.002.

Simmel, G., 1964. The Sociology of Georg Simmel. Ed. by K.H. Wolff. Glencoe, Illinois: The Free Press.

Strijbos, J.W. \& De Laat, M.F., 2010. Developing the role concept for computer-supported collaborative learning: An explorative synthesis. Computers in human behavior [Online], 26(4), pp.495-505. Available from: https://doi.org/10.1016/j.chb.2009.08.014.

Strijbos, J.W., Martens, R.L., Jochems, W.M., \& Broers, N.J., 2004. The Effect of Functional Roles on Group Efficiency: Using Multilevel Modeling and Content Analysis to Investigate Computer-Supported Collaboration in Small Groups. Small group research [Online], 35(2), pp.195-229. Available from: https://doi.org/10.1177/1046496403260843.

Strijbos, J.W. \& Weinberger, A., 2010. Emerging and scripted roles in computer-supported collaborative learning. Computers in human behavior [Online], 26(4), pp.491-494. Available from: https://doi.org/10.1016/j.chb.2009.08.006.

Tajfel, H. \& Turner, J., 1979. An integrative theory of intergroup conflict. In: W.G. Austin \& S. Worchel, eds. The social psychology of intergroup relations. Monterey, Calif: Brooks/Cole Pub. Co. Chap. 3, pp.33-47.

Therborn, G., 2012. The killing fields of inequality. International journal of health services : planning, administration, evaluation [Online], 42(4), pp.579-589. Available from: https:// doi.org/10.3898/136266209789024960. 
Tuckman, B.W., 1965. Developmental sequence in small groups. Psychological bulletin [Online], 63(6), pp.384-399. Available from: https://doi.org/10.1037/h0022100.

Tuckman, B.W. \& Jensen, M.A.C., 1977. Stages of Small-Group Development. Group $\& 3$ organization studies [Online], 2(4), pp.419-427. Available from: https://doi.org/10 .1177/ 105960117700200404.

Turner, J.C., Hogg, M.A., Oakes, P.J., Reicher, S.D., \& Wetherell, M.S., 1987. Rediscovering the social group: A self-categorization theory. New York: Basil Blackwell.

Waters, J. \& Gasson, S., 2005. Strategies employed by participants in virtual learning communities. Proceedings of the annual hawaii international conference on system sciences [Online]. Vol. 2. IEEE Computer Society, p.3b. Available from: https://doi .org/10.1109/HICSS . 2005.564.

Welser, H.T., Cosley, D., Kossinets, G., Lin, A., Dokshin, F., Gay, G., \& Smith, M., 2011. Finding social roles in Wikipedia. Acm international conference proceeding series [Online], pp.122-129. Available from: https://doi.org/10.1145/1940761.1940778.

Welser, H.T., Gleave, E., \& Fisher, D., 2007. Visualizing the Signatures of Social Roles in Online Discussion Groups. Journal of social structure, 8(2), pp.1-32.

White, H.C., Boorman, S.A., \& Breiger, R.L., 1976. Social Structure from Multiple Networks. I. Blockmodels of Roles and Positions. American journal of sociology [Online], 81(4), pp.730-780. Available from: http://www.jstor.org/stable/2777596.

Whittaker, S., Terveen, L., Hill, W., \& Cherny, L., 1998. The dynamics of mass interaction. Proceedings of the 1998 acm conference on computer supported cooperative work (rss) [Online], pp.257-264. Available from: https://doi.org/10.1145/289444.289500.

Yee, N., 2006. The Psychology of Massively Multi-User Online Role-Playing Games: Motivations, Emotional Investment, Relationships and Problematic Usage. In: R. Schroeder \& A.-S. Axelsson, eds. Avatars at work and play: collaboration and interaction in shared virtual environments. London: Springer, pp.187-207.

Zhao, Y., Wang, G., Yu, P.S., Liu, S., \& Zhang, S., 2013. Inferring social roles and statuses in social networks. Proceedings of the acm sigkdd international conference on knowledge discovery and data mining [Online], pp.695-703. Available from: https://doi.org/10.1145/2487575. 2487597. 


\section{A Classic communication roles introduced by Benne and Sheats (1948)}

Benne and Sheats (1948) identified three role groups each being comprised of several communication roles.

\section{A.1 Group task roles}

Group task roles focus on completing the group's goal.

1. Initiator-contributor provides new and keen insight and ideas to the group, and relates statements made by one group member to another.

2. Information seeker asks for clarification and ensures that the group has accurate and relevant information.

3. Opinion seeker is interested in understanding the group's values.

4. Information giver provides helpful information based on authoritative understanding or specific expertise.

5. Opinion giver offers suggestions and insight on how the group can employ its values while making specific decisions

6. Elaborator expands on others' ideas in meaningful ways, thinks about practical implementation of a decision.

7. Coordinator relates statements made by one group member to another, coordinates group activities.

8. Orienter shows where the group has been in an effort to understand where the group is right now, points out when the group has gotten completely off topic and try to refocus the group.

9. Evaluator/Critic assesses the actual functionality of the group and the decisions that it makes by higher standards.

10. Energizer stimulates the group to take action.

11. Procedural technician ensures that the routine tasks of the group get accomplished.

12. Recorder takes notes in order to help the team understand its own decision making process. 


\section{A.2 Group-building and maintenance roles}

Group-building and maintenance roles focus on building interpersonal relationships and maintaining harmony.

1. Encourager fosters environment where alternative ideas are welcomed. Encourages individuals to come up with new ideas. Praises group or team members for the ideas they generate.

2. Harmonizer ensure that the group effectively handles conflict.

3. Compromiser realises that her ideas are in conflict with another person or faction of the group, seeks out for a compromise.

4. Gatekeeper ensure that all participants are freely and openly involved in the group's decision-making.

5. Standard setter ensures that decision-making process meets a certain quality level.

6. Commentator evaluates team-working ability of the group.

7. Follower serves as an audience for the decision making process during group discussions.

\section{A.3 Self-centered roles}

Self-centered roles focus on disrupting interactions and preventing the group from reaching its goals.

1. Aggressor improves her own standing within the group by taking others down (e.g deflating the status of others, showing envy toward another's contribution by trying to take credit for it,)

2. Blocker hates everything the group is doing, rejects everything the group recommends, keeps rehashing group or team decisions that have been long since decided.

3. Recognition-seeker showing how she is such a vital person in the group by trumpeting her achievements.

4. Self-confessor ees the group or team as her own therapy session, self-discloses inappropriate information to group members during meetings.

5. Playboy/Playgirl actively disrupts the decision-making process through horseplay.

6. Dominator highly manipulative, attempts to coerce those in subordinate status positions to her stance within the group, sees their own position within the group as more superior than other group members. 
7. Help-seeker downplay her own ability to contribute to the group by making other group members care for her or him.

8. Special interest pleader speaks on behalf of another interest group (e.g., small businesses, labor, gender, race, etc.) which distracts the group.

\section{B Classic communication roles introduced by Bales (1950)}

Bales (1950) developed a coding scheme for interaction patterns and grouped these behaviours into three categories.

\section{B.1 Neutral task behaviours}

Task behaviours are interactions directed at task completion.

1. Giving suggestions Proposing particular directions, or making opportunities for other individuals to contribute to the discussion, which imply autonomy for other.

2. Giving opinions Expressing one's own feelings, ideas, and wishes, or evaluating and analysing those of other individuals.

3. Giving information Providing orientation by repeating or rephrasing previous contributions, or clarifying issues, and contributing new facts.

4. Asking for information Seeking clarifications of particular points or issues, asking for repetition and orientation.

5. Asking for opinion Asking about individuals's feelings, wishes, analysis, and evaluations.

6. Asking for suggestions Looking for ways of taking action and seeking ideas or new directions.

\section{B.2 Positive socio-emotional behaviours}

Positive socio-emotional behaviours are directed at interpersonal relations and restore harmony within the group.

1. Giving support Building on suggestions or showing acceptance of suggestions that other individuals have made. Showing solidarity, raising other's status, giving help and reward.

2. Joking Showing tension release and satisfaction and laughing.

3. Agreeing Showing passive acceptance, understanding, concurring, and complying. 


\section{B.3 Negative socio-emotional behaviours}

Positive socio-emotional behaviours are directed at interpersonal relations and cause conflict within the group.

1. Showing disagreement Resistance or rejection of ideas, withholding help or attacking other individuals.

2. Showing tension Asking for help, withdrawing out of the field.

3. Showing antagonism Deflating other's status, defending or asserting self.

\section{Classic communication roles introduced by Belbin (2010)}

1. Coordinator clarified goals, allocates tasks and expresses the conclusions of the group.

2. Shaper pushes the group towards agreement.

3. Plant advances proposals and makes suggestions.

4. Monitor/Evaluator analyses problems and assesses each person's contributions.

5. Implementer gets on with the job at hand, transforming talk into practical activity.

6. Team worker gives support and help to others.

7. Resource investigator negotiates with outsiders to locate rsources or information.

8. Completer pushes the group towards meeting schedules and targets.

\section{Definition and mapping of empirical roles to meta-roles}

Our theoretical framework of communication roles is based on roles detected by previous empirical research. Here, we describe the reviewed studies and the detected roles, and group them into our three meta-roles socialiser, self-seeker and group supporter. For a better overview, we group studies based on the type of communication network they analysed. We note that most roles that do not match one of the meta-roles (undefined roles) allude to the missing clustering dimension which we added in the extended framework. In other cases, undefined roles are not defined in terms of communication 
behaviour but in terms of aspect that are irrelevent for the conceptualisation of communication roles, such as time spent on the online platform or amount of paid membership fees.

\section{D.1 Online discussion forum Usenet}

Usenet is an online discussion forum where users can join topic-related discussion groups. It was mainly used in the early 2000s. In August 2020, Usenet recorded 170.56M postings. For comparison, on Facebook, 350M photos are on averaged uploaded every day.

\section{D.1.1 Brush et al. (2005)}

Brush et al. (2005) conducted a survey among Usenet users about their frequency and type of usage of the platform. Users had to answer questions like 'I often provide answers to other individuals's questions' on a likert-scale. These self-reports were correlated with log measures of users' platform behaviour, such as frequency of platform visits. Results revealed that the survey answers matched users' real-world activity patterns. Since roles are mainly defined based on an individual's frequency of usage, which is unrelated to her interactions with others, communication patterns cannot be detected. As a result, many of the authors' roles cannot be matched to our meta-roles.

Socialiser None of the detected roles matched this meta-role.

\section{Self-seeker}

- The questioner asks questions but does not reply to other individuals's questions.

- The reader reads messages but neither provides replies nor asks questions.

\section{Group supporter}

- The low-volume replier answers other individuals's questions but does not consider herself to be a key contributor.

\section{Undefined roles}

- The disengaged observer answered 'neutral', 'disagree', or 'strongly disagree' to all the survey questions that asked about whether she read or posted messages.

- The key contributor most commonly visits the newsgroup search homepage and author profile. 


\section{D.1.2 Combs Turner et al. (2005)}

Combs Turner et al. (2005) visually inspected descriptive statistics of users' posting activities, such as the number of sent messages and the number of active days. Results revealed qualitative patterns in these descriptive statistics which the authors used to group users into roles.

\section{Socialiser}

- The conversationalist enjoys discussing and communion. She generates valuable social interaction, a sense of belonging for other members, and a sense of community.

\section{Self-seeker}

- The trolldraws others into useless discussions. Mostly initiates threads with seemingly legitimate questions or conversation starters.

- The questioner seeks help from otehrs by posting new threads.

- The spammer posts irrelevant messages. She initiates high volumes of initiated threads, in which she contributes a single message.

- The flame warrior debates harshly and negatively and violates the open spirit of conversation. Her aim is to 'win' an argument and thereby make herself appear superior to others involved in the conversation.

\section{Group supporter}

- The answer person provides advice to others without the promise of a return on her investment.

\section{Undefined roles}

- The binary poster uses automated tools to post hundreds of parts of binary files (such as music tracks and movies) to newsgroups. She uses Usenet as a file-sharing space and not to communicate.

\section{D.1.3 D. Fisher (2005)}

D. Fisher (2005) selected four distinct sub-forums with distinct interaction cultures, respectively, and tested whether communication was different between these forums. First, they handcoded user messages to establish a ground truth of communication roles. Second, the authors constructed communication networks from the user interactions in 
each sub-forum. They compared the sub-forums in terms of degree distribution and egonetworks of the individual users. Results revealed that the sub-forums different in terms of network characteristics, and these differences matched differences in the handcoded messages. The authors concluded that distinctive communication behaviour emerges within every sub-forum and users of one sub-forum can be assigned the same role.

Socialiser None of the detected roles matched this meta-role.

\section{Self-seeker}

- The flamer insults others and often reciprocates messages.

- The political discussant is similar to the flamer in insulting others but does not often reciprocate messages.

\section{Group supporter}

- The answer person (technical support) answers other individuals's questions.

- The social supporter helps new users and keeps in touch with active users.

\section{D.1.4 Combs Turner and K.E. Fisher (2006)}

Combs Turner and K.E. Fisher (2006) observed discussions in preselected forums, asking comprehension questions to the forum's manager, running focus groups with members of the forum, and visually analysing temporal frequency plots showing the number of initiated and answered messages per user and day.

Socialiser None of the detected roles matched this meta-role.

Self-seeker None of the detected roles matched this meta-role.

\section{Group supporter}

- The mentor helps other users and enjoys a good reputation in the community. She is highly active and can advocate topics and solutions.

- The manager ensures that individuals adhere to the rules and norms of the community. This may sometimes make her unpopular among the other users.

- The mogul answers complex questions and helps when problems escalate. 


\section{D.1.5 Welser et al. (2007)}

Welser et al. (2007) handcoded user messages to establish a ground truth of the answer person role. They constructed a communications networks from user interactions and extracted degree- and temporal frequency distributions from the users' ego-networks. They used a logit regression to show that these three features can predict whether a user is an answer person or not.

Socialiser None of the detected roles matched this meta-role.

Self-seeker None of the detected roles matched this meta-role.

\section{Group supporter}

- The answer person anwers other individuals's questions.

\section{D.1.6 Gleave et al. (2009)}

Gleave et al. (2009) handcoded user messages to establish a ground truth of the communication roles defined in Welser et al. (2007) for Usenet and Welser et al. (2011) for Wikipedia (see section D.2). The authors constructed a communication network from user interactions and visually related structural properties of users' ego-networks (e.g., density of edges in periphery) to the handcoded messages.

\section{Socialiser}

- The discussion person frequently reciprocates messages from many users.

Self-seeker None of the detected roles matched this meta-role.

\section{Group supporter}

- The answer person anwers other individuals's ques- tions.

- The discussion catalyst initiates new discussion threads that other individuals pick up on.

- The substantive expert resolves disputes and contributes to content-related discussions.

- The technical editor enforces formatting standards. 


\section{D.1.7 Golder and Donath (2004)}

Golder and Donath (2004) handcoded user messages along the concepts of communicative competence, ability to behave according to social norms (Hymes, 1974), participation inequality (Whittaker et al., 1998), participation rate, and Jones and Pittman (1982)'s five strategies for interaction: intimidation, supplication, ingratiation, exemplification and self-promotion. Based on these factors users were grouped into roles.

Socialiser None of the detected roles matched this meta-role.

\section{Self-seeker}

- The celebrity enforces changes in the community, e.g., by defining community standards and bringing about short-term change.

- The flamer intimidates others and is aggressive. It is not her aim to become a accepted member of the community and she is not a competend communicator.

- The troll deceives others, lures them into useless discussions, and is not interested in the discussion topic. In contrast to the flamer communicative competence is the troll's most important trait.

- The ranter deceives others, lures them into useless discussions, and is interested in the discussion topic. Unlike a troll, the ranter has an agenda. She wants to be in the limelight and be admired by others.

Group supporter None of the detected roles matched this meta-role.

\section{Undefined roles}

- The lurker and the 'newbie' are passive users who mostly read messages rather than posting something. So no communication activity is visible.

\section{D.1.8 Nolker and Zhou (2005)}

Nolker and Zhou (2005) conceptually pre-defined roles of users in an online discussion forum and manually compared them with selected topological network measures of users from the communication network of all users.

\section{Socialiser}

- The chatter posts a lot of messages to a few individuals but does not contribute to the community conversation as a whole. 
Self-seeker None of the detected roles matched this meta-role.

\section{Group supporter}

- The 'motivator keeps conversations going.

- The leader spreads knowledge and works towards a cohesive community.

\section{D.2 Wikipedia}

Wikipedia is a crowd-sourced online encyclopedia. Everyone can write an article on a topic of her choice or modify an existing one. This work is then discussed among editors in the Wikipedia community and finally published on the website.

\section{D.2.1 Welser et al. (2011)}

Welser et al. (2011) handcoded user messages to establish a ground truth of communication roles. The authors compared the frequency distributions of edits across name spaces between different role members. They also constructed a communication network of user interactions and visually compared the ego-networks of some editors, exemplary for a role. Results revealed that qualitative roles based on handcoded messages matched patterns in the network and the frequency distribution.

\section{D.2.2 Welser et al. (2011)}

Whereas Welser et al. (2011) used a visual comparison of ego-networks networks, Welser et al. (2011) defined quantitative network measures to describe communication roles. The users used a to infer handcoded content groups of user messages (roles) from structural properties of users' ego-networks.

\section{Socialiser}

- The social network uses social chitchat rather article collaboration to build strong relationships with other users. They utilize 'User Talk' extensively, make 'Wikifriends', and create elaborate profiles that showcase their Wikipedia personalities.

Self-seeker None of the detected roles matched this meta-role.

\section{Group supporter}

- The substantive expert resolves content-related disputes and contributes knowledge to the discussion. 
- The technical editor enforces formatting standards.

- The counter vandalism editor sanctions users who do not comply to the rules of the community.

\section{D.3 Online learning environment}

Online learning environments (OLE) such as 'Moodle' or 'Blackboard' are passwordsecured platforms where teachers can upload learning material for their students and can discuss questions with them. Often, separate forums exist where student groups can interact and work on course projects.

\section{D.3.1 Waters and Gasson (2005)}

Waters and Gasson (2005) handcoded user messages along an extended version of Garrison et al. (2000)'s coding dimensions of teaching, social, and cognitive. Based on this coding, the users were qualitatively assigned a role.

\section{Socialiser}

- The initiator maintains a social network of individuals by sending work-unrelated messages to many individuals. She look for points of connection such as affiliations, occupations or hobbies.

- The contributor contributes to the debate without changing its course. She contributes in a minimal way to fulfill her 'grade-earning' duties.

\section{Self-seeker}

- The knowledge elicitor seeks help from others.

- The vicarious acknowledger seeks social recognition from others for her achievements.

- The passive learner freeloads and does not contribute to the community.

\section{Group supporter}

- The facilitator keeps the debate moving by encouraging other users to participate and by solving problems, e.g., she warns the community if the discussion is wandering off topic.

- The complicator provides an alternative perspective by reformulating a problem or uncovering inconsistencies in an argument. 
- The closer synthesizes open issues. She pulls together a final or coherent answer to the question and often brings a debate to a conclusion. She reconciles differences and combines threads of arguments.

\section{D.3.2 Strijbos and De Laat (2010)}

Strijbos and De Laat (2010) pre-defined roles based on a literature review on computersupported collaborative learning environments and matched these roles to handcoded user messages. Groups only included 7-10 students which weakens the network perspective.

Socialiser None of the detected roles matched this meta-role.

\section{Self-seeker}

- The generator takes the initiative to fulfill her personal goals. She jumps right in to make proposals and devotes a lot of energy and time to the project.

- The lurker pretends to contribute to the project but in fact tries to fulfill her goals by being passive.

\section{Group supporter}

- The pillar engages in group activities to get the collaborative task done.

- The hanger-on aims to contribute to the collaborative tasks but does not manage to live up to her own expectations.

\section{D.4 Online discussions: miscellenous platforms and topics}

Besides research on Usenet (see section ??), the online dicussion platform from the early 2000s, other, more modern platforms, such as Facebook, and topic-specific private forums have been used to study communication roles.

\section{D.4.1 de Valck et al. (2009)}

de Valck et al. (2009) studied a virtual community on culinary matters where users exchange information on cooking products and recipes. The authors conducted a survey among users about their usage of the discussion forum (e.g., amount of supplied information to discussion). The authors applied k-means clustering to the survey scores and compared the resulting clusters with an ANOVA. Results revealed that the clusters were significantly different from each other and the authors concluded that the clusters represent roles. 


\section{Socialiser}

- The conversationalist is socially involved but does not have high expertise

- The hobbyist uses the community for leisure and entertainment, e.g., by writing guest book entries.

\section{Self-seeker}

- The functionalist retrieves information from the community but does not contribute often.

- The opportunist retrieves information from the community but does not contribute at all.

\section{Group supporter}

- The core member extensively contributes knowledge to and retrieves knowledge from the community.

- The informationalist moderately contributes knowledge to and retrieves knowledge from the commu- nity.

\section{D.4.2 Seraj (2012)}

Seraj (2012) analysed a private online community on aviation. The author handcoded user messages and conducted user interviews. Based on these results, users were qualitatively grouped into roles.

\section{Socialiser}

- The player entertains the community. She generates social value by making jokes and raising fun content.

Self-seeker None of the detected roles matched this meta-role.

\section{Group supporter}

- The seeker gets the discussion going by asking questions. She drives content value.

- The governor ensures that users comply to the rules and norms of the community. She also ensures the quality of content.

- The educator shares her knowledge with the community and actively co-creates content. 
- The challenger questions the provided in- formation and provides alternative perspectives. She increases content-quality, eliminates biases, and keeps the community democratic and creative.

- The appraiser recognizes the contribution of other users and encourages them to get further involved in the community.

- The innovator provides an alternative perspective. She brings excitement and novelty to the community and enhances its social value.

\section{D.4.3 Pfeil et al. (2011)}

Pfeil et al. (2011) detected roles of users in an online-support community for older individuals. The authors handcoded user messages along five dimensions, including empathetic content and user-centered content. They constructed a communication network from user interactions and computed regular equivalent users with the Continuous REGE algorithm of the UCINET software. They compared the resulting the handcoded user groups with the REGE results and found a match.

Socialiser None of the detected roles matched this meta-role.

\section{Self-seeker}

- The active member mainly talks about herself and posts a lot.

- The passive member is like the active member with a smaller number of postings.

\section{Group supporter}

- The moderating supporter provides support to other users and has a strong interest in the community.

- The central supporter provides and receives support to/from other users.

- The technical expert provides support to other users but does not receive much support back in return.

\section{Undefined roles}

- The visitor has a low volume of postings and rather reads messages. Because she does not communicate a lot she cannot be assigned a meta-role. 


\section{D.4.4 Füller et al. (2014)}

Füller et al. (2014) studied roles in a jewellery-innovation contest community where users could upload their jewellery designs, comment, and vote on each other ideas. The authors build a communication network from user interactions, and applied k-means and hierarchical clustering to selected topological measures of users' ego-networks (e.g., out-degree) and to descriptive features of users' platform usage (e.g., number of posted ideas). The resulting clusters were compared with an ANOVA and were found to be significantly different. The authors used the results to assign the same role to users of the same cluster.

\section{Socialiser}

- The socialiser contributes with social interactions rather than ideas.

Self-seeker None of the detected roles matched this meta-role.

\section{Group supporter}

- The master provides a lot of useful postings for other users.

\section{Undefined roles}

- The passive does not actively participate in the innovation-contest community through a high number of comments or designs, or through providing highly attractive designs that capture considerable community attention.

- The idea generator uploads a lot of design suggestions but does not actively participate in communication or facilitates information exchange or social relationships, which can be seen from her few, if any, outgoing relationships.

- The efficient contributor focuses on idea-generating activities rather than active commenting behavior. With fewer submitted ideas, this role is able to attract the same level of attention as the 'idea generator' with a very high number of submitted designs.

\section{D.4.5 Kozinets (1999)}

Kozinets (1999) conducted a qualitative analysis of virtual communities of consumption where individuals with the same interest in a certain product interact. The authors qualitatively observe user interactions and based on these interactions group users into four roles along two dimensions: intensity of user-product and user-user relation, respectively. The authors suggest different marketing strategies to target the individual roles. 


\section{Socialiser}

- the mingler focuses on short-term satisfaction and values social interaction.

- The insider values social interactions. For her, social contact of online communication is in itself a valuable reinforcement

\section{Self-seeker}

- The tourist retrieves information from the community but does not contribute at all. Her communication is individualistic and focuses on short-term personal gain. She lacks strong social ties to the group.

- The devotee is only interested in the discussion topic but not in socialising.

Group supporter None of the detected roles matched this meta-role.

\section{D.4.6 Benamar et al. (2017)}

Benamar et al. (2017) analysed a Facebook group about a cooking product. First, the authors conducted an activity analysis where they used a statistical clustering method to group similar users based on activity features such as number of posts and number of likes. Second, they constructed a communication network from user interactions and computed some pre-selected topological network measures for each user (e.g., outdegree). Third, they handcoded user postings resulting in 24 themes. They then computed the frequencies with which users used these themes and grouped users of similar frequency patterns. These qualitative groups matched the roles detected by network and frequency measures qualitatively.

\section{Socialiser}

- The generalist focuses on community life and social intercourse.

- The friendly product fan engages in animation activities, and community life. She wants to create social or emotional connections with other group members.

- The amateur seeks to share aspects of her daily life with the group.

\section{Self-seeker}

- The product fan learner uses the community to improve her own skills and knowledge.

- The amateur learner uses the community to share her achievements.

- The friendly learner uses the community to improve her own skills and knowledge. 


\section{Group supporter}

- The gatekeeper ensures that the group identity and values are in place. She emphasizes rules and standards, and defends the community from potential threats from competing groups.

- The mentor helps other users with the technical functionalities of the forum.

- The product ambassador shares information to improve other users' knowledge.

\section{D.5 Dyadic communication}

Some of the previous studies have used the nearest-neighbour networks of nodes in a communication network to detect their roles. these nearest-neighbour networks represent the dyadic communication of the focal node with her neighbours. So far, previous studies have enriched these dyadic measures with others computed on the global network and the content of the exchanged messages. In contrast to these studies, the work of this section only uses nearest-neighbour networks for role detection without any other measures.

\section{D.5.1 Box-Steffensmeier et al. (2018)}

Box-Steffensmeier et al. (2018) analysed communication between political interest groups in forming coalitions.

The authors constructed a communication network from interactions between interst groups and extracted ego-networks for each node. Based on theoretical considerations, they selected topological network measures which were assumed to capture behavioural patterns in the coalition forming process. The authors applied an ego-exponential random graph model to predict the topological measures of one node from the measures of another node. If the prediction was successful the two nodes were assigned the same role.

Socialiser None of the detected roles matched this meta-role.

\section{Self-seeker}

- The teammate does not cooperate with other interest groups because their goals are not aligned with hers. She is an industry-based interest group.

- The peripheral specialist only cooperates with other interest groups whose goals are as specialised as hers. She is a pro-environment interest with a niche focus. 


\section{Group supporter}

- The coordinator mediates coalitions between others. She is a pro-environment interest group.

\section{D.6 Online games}

\section{D.6.1 Bartle (1996)}

Bartle (1996) qualitatively observed interactions between players, i.e. conversations in the game chat. The author qualitatively grouped these interactions into roles which are defined along two dimensions. The first dimension indicates whether a player is rather oriented towards other players or towards the gaming world and the second dimension indicates whether the player prefers acting on her own over interacting with other players.

\section{Socialiser}

- The socialiser emphasizes with individuals and enjoys jokes. She does not focus on rising levels or killing.

\section{Self-seeker}

- The killer annoys other players by demonstrating her superiority in game skills.

- The achiever aims to rise in game levels. She wants to gain points in the game.

- The explorer aims to learn more about the game and get new ideas rather than to socialise.

Group supporter None of the detected roles matched this meta-role.

\section{D.6.2 Yee (2006)}

Yee (2006) conducted a survey among members of online role-playing games where participants provided insights into their motivation to game and their relationships with other gamers (e.g., 'I like to feel powerful in the game.'). The authors ran a factor analysis on the survey scores to group players into roles.

\section{Socialiser}

- Players valuing immersion enjoys the story-telling aspect of the game. they enjoy to be 'someone else' and to dive into the story of the game.

- Relationship-focused players forms supportive relation- ships with others. The disclose real-life problems to other players. 


\section{Self-seeker}

- Players focused on achievement want to become powerful in the game.

- Players focused on manipulation manipulate other players for her personal gains (e.g. deceiving).

Group supporter None of the detected roles matched this meta-role.

\section{Undefined roles}

- Players valuing escapism use the virtual world to temporarily avoid, forget about, and escape from real-life stress and problems. We note the clustered structure between the gaming world and the real one.

\section{D.6.3 Ang and Zaphiris (2010)}

Ang and Zaphiris (2010) manually coded messages in an online game chat along predefined types of interactions such as 'group management' or 'ask for help'. They constructed a communication network from user interactions and applied a block model to it to group structurally equivalent nodes. Results revealed that the blocks had distinct profiles in terms of prevalent types of interactions which were then used to define the communication roles.

\section{Socialiser}

- The social player nurtures a friendly and welcoming atmosphere within the community.

\section{Self-seeker}

- The free-loader uses other players to advance in the game. She does feel part of the group because she only uses the guild as an instrumental tool for her task-related interactions.

\section{Group supporter}

- The knowledge player helps other players and encourages the group to do so, too.

\section{Undefined roles}

- The newbie is a peripheral player who is new to the guild and the whole game in general. 